\title{
Facilitating sustainability control in SMEs through the implementation of an environmental management system
}

\section{Leanne Johnstone ${ }^{1}$ (iD}

Accepted: 20 September 2021 / Published online: 9 October 2021

(c) The Author(s) 2021

\begin{abstract}
This paper explores the characteristic type and use of sustainability control in small to medium sized enterprises (SMEs) through the implementation of an environmental management system, formally certified to ISO 14001. Through a qualitative study of 18 SMEs and seven auditors operating in Northern Europe, the paper draws on the theoretical framework of sustainability control as an analytical tool to explore the interplay between the formal design of control instruments and the operational use of these in practice for the studied SMEs. The study finds that both the formalised control instrument design and operational use of these controls by employees are characteristically formal and procedure based for ISO 14001 certification. Nevertheless, environmental management in daily tasks is also achieved by engaging non-managerial employees through their passionate interests and intrinsic motivations. In extension to previous sustainability control research, the findings emphasise that local level operator knowledge is not only the product of formalised control system design, and that external factors are also important for guiding employee behaviour in situ. This proposes that daily working tasks are achieved through a combination of organisational and extra-organisational individual values and beliefs about sustainability. Particularly, engaging non-managerial employees in SMEs through a combination of extrinsic and intrinsic rewards appears valuable for sustainable futures. Therefore, in addition to compliance-driven controls, SME owner-managers should ensure supportive structures where employees are given the autonomy to be creative and innovative.
\end{abstract}

Keywords Control in situ · Environmental engagement $\cdot$ Environmental management system $\cdot$ ISO $14001 \cdot$ SMEs $\cdot$ Sustainability control

JEL Classification M19 · M41 · M42

Leanne Johnstone

leanne.johnstone@oru.se

1 Department of Business Administration, Örebro University School of Business, Örebro, Sweden 


\section{Introduction}

As the biggest sector of society, small to medium enterprises (SMEs) contribute to most of Europe's pollution (Kearins et al., 2010), and their negative impact on a global scale is great (Lewis et al., 2015). Nevertheless, much remains to be known about how SMEs control for sustainability as an emerging field of interest (see Gibassier \& Alcouffe, 2018; Ghosh et al., 2019; Johnstone, 2020a; Pelz, 2019). To date, most sustainability control research focuses on established control systems in larger firms (e.g. Henri \& Journeault, 2010), or does not differentiate between firm size in study samples (e.g. Pondeville et al., 2013; Riccaboni \& Leone, 2010). However, studies suggest that the unique features that characterise smaller firms result in less sophisticated control systems (Kruis et al., 2016) based on interpersonal factors (see Bedford \& Malmi, 2015) and that the management control tools developed for larger firms are difficult for smaller ones to operationalise (Lavia López \& Hiebl, 2014; Stubblefield Loucks et al., 2010). Nevertheless, few empirical studies exist to address such claims (Johnstone, 2020a).

Beyond the management control literature, SMEs are presented as having distinct characteristics in terms of concentrated ownership, flatter organisational structures and limited resources, among others (Hillary, 2004; Stubblefield Loucks et al., 2010). These unique characteristics arguably effect their approach to sustainability initiatives (Fassin, 2008). On the one hand, some suggest sustainability initiatives in SMEs are costly and resource consuming, driven as a reaction to customer or legislative requirements (see Perez-Sanchez et al., 2003; Santos et al., 2011). On the other hand, others present sustainability initiatives in SMEs as tied to the values of owner-managers that guide internal action through proactive strategies (see Spence, 2016; Stubblefield Loucks et al., 2010).

The unique characteristics of the SME sector also have implications for the type and nature of sustainability control (Johnstone, 2020a). While the nature of control in SMEs is typically presented as flexible as opposed to tight (see e.g. Halme \& Korpela, 2014), due to the aforementioned characteristics which are more suited to responsiveness and personal relationships, ${ }^{1}$ the characteristic type of control in SMEs remains unclear. While some suggest that control is less formal in SMEs (e.g. Moore \& Spence, 2006; Scapens, 2006), others find that SMEs mimic the formalised control systems of larger customers, viewing these as the best course of action for improved sustainable performance (e.g. Johnstone \& Hallberg, 2020; Nawrocka, 2008). Additionally, there is the viewpoint that control in smaller firms becomes increasingly formal over time as internal systems become more developed (Groen et al., 2012).

\footnotetext{
1 Although studies into management control in SMEs are limited (Johnstone, 2020a), such findings are in line with the family business literature which suggests that management control, in its functionalistic and bureaucratic sense based on tight control, is less applicable given the unique characteristics of family firms in terms of their shorter communication channels and flexible decision-making processes (see e.g. Duréndez et al., 2016; Quinn et al., 2018).
} 
Understanding the characteristic type of sustainability control in SMEs and how it is used is important for both research and practice. Given the collective pollution scale of SMEs, more informed knowledge about how sustainability initiatives are implemented through internal systems can improve future sustainability performance in SMEs. Moreover, due to wider supply chain effects and the global importance of the sustainable development goals (SDGs), SMEs are often put under pressure by larger customers to implement sustainable management systems (see Johnstone, 2020b; Nawrocka, 2008Wu 2017). Nevertheless, much remains to be known about how SMEs control for sustainability in practice, and furthermore if this differs from larger firms (see Ghosh et al., 2019).

To address these gaps, this study asks: How does the implementation of an environmental management system in SMEs affect the characteristic type and use of sustainability control? This question focuses on the broad characteristics of sustainability control, rather than specific control typologies and their interaction effects. This helps outline how formal and informal controls are used to implement sustainability initiatives (see also Arjaliès \& Mundy, 2013) as an important first step for analysing the role of sustainability control in SMEs as a distinct organisational form (Johnstone, 2020a). Not only does the research question focus on the characteristic type of control in SMEs implementing an EMS, it addresses how employees use formalised controls, as well as contributes to the (re)development process of said controls in their daily tasks. Nevertheless, what differentiates this paper from previous sustainability control studies (e.g. Arjaliès \& Mundy, 2013; Journeault et al., 2016), is the use of a theoretical framework which implies that operational action (i.e. sustainable behaviour within the SME context) is the product of both intra and extra-organisational factors (Johnstone, 2019).

The 'framework of sustainability control' (Johnstone, 2019) is applied in this research to frame the findings in terms of how the formalised control instrumentsboth formal and informal-are applied and used at the operational level in SMEs through the introduction of an EMS. While the framework builds upon previous works in the accounting field which use Adler and Borys' (1996) concepts of enabling and coercive bureaucracy (e.g. Baird et al., 2017; Wouters \& Wilderom, 2008), it additionally suggests that focusing on how employees perceive enabling and coercive controls provides a partial understanding. Specifically, Johnstone's framework furthers that management control for sustainability is not only facilitated in the organisation through the design of formalised controls that relate to organisational beliefs and values and how these are perceived by non-managerial employees, but also by the individual employee's (managers and non-managers) own sustainability beliefs and values, which may be borne from the extra-organisational context. Thus, the framework is used as an analytical tool to emphasise that extant management control system (MCS) frameworks-from a strategic or managerial perspective (e.g.Adib et al., 2020; Arjaliès \& Mundy, 2013; Rodrigue et al., 2013; Wijethilake \& Upadhaya, 2020) - are limited in explaining how sustainability control is received, used and developed in situ-at the operational level—for sustainable performance improvements. This is because controlling for sustainability increasingly has intra 
and extra-organisational dimensions which affect the design and use of sustainability controls beyond managerial tiers (see also Heggen et al., 2018).

Through a qualitative cross-case interview approach of representatives from eighteen ISO 14001-certified SMEs and seven ISO 14001 auditors operating in the UK, Ireland and Sweden, the study finds that both the formalised control instruments designed for EMS implementation in SMEs and the operational use of these controls by employees are (generally) based on tight control and compliance-driven measures. This suggests that the implementation of EMS through certification (i.e. ISO 14001) in SMEs primarily results in the formalisation of system design and work processes (Nawrocka, 2008). Not only does this stand in contrast to the suggestion that control in SMEs is characteristically informal and based on interpersonal communication which may be ad hoc in nature (e.g. Halme \& Korpela, 2014), it also contrasts with the latest version of ISO 14001 which is moving towards flexible solutions and enabling environmental management throughout all organisational tiers (ISO 14001: 2015). Nevertheless, the findings also reveal that engaging non-managerial employees in daily work to improve environmental performance is achieved through strategies that build upon individual values. To this end, the study offers examples of reward and compensation mechanisms to engage employees through formalised controls which build upon both extrinsic and intrinsic motivations which are the product of both organisational and extra-organisational factors.

The paper begins with a literature background overviewing the broad characteristics of sustainability control and presenting the theoretical framework which guides this research. Next, the method is presented before the findings and discussion are offered. Finally, the conclusion and implications are given.

\section{Literature background}

Sustainable control systems (SCS) typify research on sustainability management control. Conceptualised as the interface between strategy and operations (Guenther et al. 2016) to guide and motivate action, as well as provide information and direction (see Johnstone, 2019; Wijethilake et al., 2018), SCS entail elements of both formal and informal control in their design (Pondeville et al., 2013). While the formal elements rest on the integration of environmental performance into corporate governance structures, documented procedures and discrete objectives, the informal aspects regard open communication channels between levels to share problems and solutions, which support the implementation and follow-up of environmental decisions, among others (Laguir et al., 2019; Pondeville et al., 2013). Particularly, informal controls regard interpersonal relations, teamwork and a participatory approach that recognises the responsibility and involvement of all employees for environmental performance (see Berry \& Rondinelli, 1998; Johnstone, 2019). For sustainability issues, the informal dimensions embodied into control system design-and/or corporate culture - are viewed as increasingly important for engaging and motivating staff in further system development (see Crutzen et al., 2017; Tung et al., 2018). Albelda Pérez et al. (2007) suggest that this can be achieved through, for example, 
intangible assets such as employee awareness, knowledge, skills and sustainability commitment (see also Johnstone, 2019).

Studies into the role of behavioural control which enables employees to perform sustainably in everyday operations are limited within sustainability control research. Particularly, little attention has been paid to how MCS "change awareness and attitudes towards more social and environmental responsible decision making, taking corporate sustainability beyond the business case" (Albelda, 2011: 81). Of those studies which do look at the behavioural implications of SCS design, various conclusions have been yielded in terms of the type and nature of control.

Norris and O'Dwyer (2004) explore how control system design influences the social responsiveness of managers, finding that informal controls (i.e. shared values and beliefs) are more suited to socially responsive decision-making than formal controls based on explicit procedures and policies. Meanwhile, Sundin and Brown (2017) investigate how environmental issues are integrated into organisational behaviour through the control system. Together, these studies find that internal control mechanisms, for example the design and use of environmental targets, are necessary for aligning the behaviour of employees (managers and non-managerial operators) and improving performance. While the behavioural effects of control system design in Sundin and Brown's study are primarily achieved through formal control tools, Norris and O'Dwyer emphasise the importance of informal control for sustainability matters. Common to both studies, however, is the notion that control is a top-down phenomenon. This, consequently, downplays the role of behavioural control from the bottom-up, by which employees at the operational level may be able to contribute to SCS (re)design through their individual values and beliefs, as well as broader sustainability knowledge and experiences (see e.g. Johnstone, 2019; Won Kim and Masumara 2017).

The explicit focus on SCS design as determining sustainable operator behaviour has been implied as partial in explaining why and how employees perform sustainably in practice. Building on the accounting as a social practice literature, Johnstone's (2019) argument is founded on the view that individual sustainability values as well as professional experiences translate into the daily work practices of operators.

First, Johnstone (2019) suggests that individual beliefs and values about sustainability as a discourse can also affect SCS (re)design and use; in this sense, changing organisational beliefs regarding sustainability from the bottom-up. Second, rather than managers as the sustainability experts, she suggests that other individuals throughout the organisational hierarchy may be better equipped to come up with sustainable solutions to operational problems at site as operational 'experts'. Together, this implies that it is not only the formalised design characteristics of SCS by managers which influence non-managerial behaviour, but that local actions by non-managerial employees may also influence the SCS development process. This stands in contrast to earlier studies that assume non-managerial behaviour in daily working tasks is the result of strategic SCS design and-in essence-managerial decisionmaking (e.g. Arjaliès \& Mundy, 2013; Gond et al., 2012; Journeault et al., 2016).

Other authors have touched on the notion that control for sustainability may also originate from the bottom-up, although explicitly through a system design which permits for flexibility in practice. For example, Wijethilake et al. (2018) suggest 
that enabling aspects of system design such as flexibility, creativity and responsiveness empower employees to participate in sustainability decision-making and subsequent performance outcomes (see also Baird et al., 2017). These design features are viewed as instrumental for solving sustainability problems given that controlling uses (e.g. following rules and instructions) can stifle innovation (Wijethilake et al., 2018). Rodrigue et al. (2013) further that employees both influence and are influenced by sustainable performance measurement systems and strategy at the plant level. Nevertheless, the focus of these studies remains within the organisational boundaries for non-managerial employees and any extra-organisational influence is only be made explicit at the strategic level of managers in terms of SCS design and corporate decision making. Thus, the idea that the values and experiences of individual employees (beyond managerial tiers and strategic SCS design) can also be utilised in the (re)development process of SCS from the bottom-up can be seen as something new. This builds upon a broader definition of sustainable 'management' control as a practice, rather than primarily management as the people in organisations who direct the actions of subordinates through control instruments (Johnstone, 2019). Consequently, a better understanding of how employees operate in situ as a combination of both formalised system design characteristics and their own sustainability values is important for a comprehensive view of sustainability control in practice.

\subsection{Theoretical framework of sustainability control}

Johnstone's framework of sustainability control (2019) emphasises the need for scholars to look at both formalised system design and daily system use for effective sustainable performance. It is built on the premise that both formally designed control instruments at the strategic level and individual employees (managers and non-managers) operationally, guide sustainability actions over time and space. It emphasises that sustainability management control, as a practice, is often the product of internal organisational beliefs and values (see e.g. Laguir et al., 2019) and individual ones, the latter of which, may also be borne from the external firm context. Not only does this imply that system design and use reside throughout organisational levels, it responds to critical viewpoints over the sustainability discourse as something broader than the firm and managerial decisions (see e.g. Gray, 2010) by explicitly incorporating externalities within a SCS framework. ${ }^{2}$ Additionally, it provides a more flexible framework for organisations characterised by different structures such as SMEs where the management of sustainable processes often relies on the knowledge and active participation of employees beyond managerial tiers and formalised control system design.

Implicitly, Johnstone's framework attaches importance to flexibility in practice as well as operators' participation and relationships with management tiers to solve

\footnotetext{
2 Most MCS frameworks are operationalised as intra-organisational domain theories, with the exception of Broadbent and Laughlin (2009) who emphasise the role of context for informing strategic level decisions within the organisation.
} 
environmental issues. This can be viewed as tied to informal control designs and participatory approaches which work together with other, more characteristically formal, controls to ensure sustainability performance outcomes (see Pondeville et al., 2013). The framework suggests that the design and use of controls for effective sustainability management (management as the management of processes) is an ongoing process, existing at both strategic and operational levels. Thus, it implies that conventional management control theoretical or conceptual frameworks such as Simons levers of control (e.g. Arjaliès \& Mundy, 2013; Journeault et al., 2016; Laguir et al., 2019; Rodrigue et al., 2013) or Malmi and Brown's management control system package (e.g. Baker et al., 2012; Crutzen et al., 2017) are limited in capturing sustainability as a discourse, which is broader than the firm and involving both managerial and non-managerial employees in system design and use.

\subsubsection{Development of the framework of sustainability control and its associated terms}

The framework of sustainability control builds on earlier management accounting and control research which used Adler and Borys' (1996) enabling and coercive bureaucracy. Although the focus in this study is on using the framework of sustainability control and the concepts therein as an analytical tool, not on Adler and Borys' coercive-enabling control per se, it is arguably important to briefly overview Johnstone's connections to the seminal work. This is necessary to clarify some important terms and concepts, and their use in this study.

Adler and Borys (1996) focus on the formalisation aspect of bureaucracy, ${ }^{3}$ proposing that corporate systems can be designed either as coercive (i.e. based on power asymmetries, compliance and constraint) or enabling (i.e. based on decentralised power and employee autonomy). These design characteristics are intended by top management to ensure desired performance is achieved. Concurrently, Adler and Borys suggest that coercive systems induce negative employee attitudes to work tasks while enabling systems induce the opposite: positive ones.

While at the time this was regarded as something new, later studies have found that enabling and coercive design characteristics exist together to improve corporate performance (e.g. Ahrens \& Chapman, 2007; Jordan \& Messner, 2012) and that designating controls as 'good' or 'bad' is not indicative of their reception by employees and/or their quality (see Tessier \& Otley, 2012). This means that in practice elements of both basic system designs work together. For example, coercive design features, such as employees following formalised well-documented procedures and routines to meet objectives, may exist alongside enabling design features, such as trusting employees to make autonomous decisions in day-to-day operational tasks to meet these objectives (see also Ahrens \& Chapman, 2007;

\footnotetext{
3 Note that Adler and Borys' (1996) work stems from the organisational literature stream. It focuses on the formalisation aspect of bureaucracy although bureaucracy also entails other elements such as specialisation and hierarchy which are also embraced under the coercive and enabling concepts to varying degrees.
} 
Jordan \& Messner, 2012). It also means that the interpretation of coercive or enabling controls by employees is a subjective experience. For example, coercive system designs may not be necessarily viewed as bad if they permit employees to achieve tasks. Nevertheless, while the focus of coercive system designs tends to be on operational employees, enabling system designs tend to look at managers (Englund \& Gerdin, 2015). To this end, there is a general lack of research looking into the effects of enabling designs on non-managerial employees (Coyte, 2019; Wouters \& Wilderom, 2008).

In addition to the design characteristics as enabling or coercive, Adler and Borys propose that there are specific design principles which differentiate between enabling and coercive systems. They suggest that action-or repair-in daily tasks is based on the operator's knowledge of both local (i.e. departmental role or function) and global (i.e. organisational objectives) information; what Adler and Borys term 'local and global transparencies'. While information in coercive systems is based on codified rules and routines as vertical flows, for enabling systems, it is based on operator autonomy and horizontal flows. For example, repair in coercively designed systems may be contingent on the operator following the formal policy and procedures of the organisation which sets the permission scope to act. In this sense, operators are unable to deviate from organisational rules and the nature of control can be regarded as characteristically 'tight'. Meanwhile, for enabling systems, repair is arguably contingent on the knowledge and experience of operators. Here, 'local' actors are more actively involved in further system design at the operational level through the enabling use of controls in practice (see Goretzki et al., 2018). Nevertheless, the permission scope to act at the operational level is arguably down to the flexibility embedded into formalised system design. To this end, Chapman and Kihn (2009) propose flexibility as a condition, rather than a design principle, given that it cannot directly affect performance on its own.

For the framework of sustainability control, it is the combination of formalised design elements at the strategic level (i.e. as enabling and/or coercive) and the reception of said elements (i.e. controls), their use and (re)development at the operational level that produce particular performance outcomes. The framework conceptualises the former as 'control over' and the latter as 'control in situ'. As an extension to earlier assumptions, within the operational level of control in situ, employees are facilitated to perform sustainably in their daily work tasks through both the formalised design characteristics (which may be enabling and/or coercive) and extraorganisational factors (which may affect their individual values and beliefs about sustainability and consequent approach to environmental management performance in situ). In this sense, operator knowledge (especially local transparency) is assumed as not only the product of formalised system design, but something more that facilitates individuals to perform sustainably. Others within the sustainability control field have touched on the notion that sustainability control is broader than strategic design in terms of the contribution of individual operators (e.g. Wijethilake et al., 2018). Nevertheless, sustainability control studies typically attribute the external impact on the design of formalised SCS at a strategic or managerial level in the form of stakeholder assessments being incorporated into decision-making (e.g. Pondeville et al., 2013; Rodrigue et al., 2013). 
Overall, the framework of sustainability control highlights the interaction between formalised SCS design and the behavioural outcomes of said design that allow employees to manage practices sustainably at the operational level. It furthermore emphasises that the construction of formalised controls as coercive or enabling may produce similar effects in terms of facilitating employees to carry out tasks in situ. Nevertheless, as an extension to previous management control research, the behavioural outcomes are not only presented in terms of the formalised design characteristics, but also the result of extra-organisational influences on operators' action in situ. This implies that management control for sustainability is not only contingent on formalised system design, but rather that employee behaviour is the result of both corporate and individual value systems that should not and cannot be separated analytically or in practice to understand how improved sustainable performance in achieved. In this sense, the framework offers something new to the field by explicating that the sustainable control of daily processes is also down to non-managerial employees at the operational level, thus building on the accounting as a social practice literature stream while attempting to reconcile both managerial and critical positions by adopting a 'middle of the road approach' (see Deegan, 2017).

\subsubsection{Control in situ}

The framework of sustainability control attaches importance to the actual use of formalised design features by individual operators to facilitate sustainable performance; concurrently recognising that formalised system design is not enough in itself to explain operational action. This extends assumptions in the accounting as a social practice literature, which implies formalised system designs as the means to guide employee behaviour (e.g. Ahrens \& Chapman, 2007; Burns \& Scapens, 2000). It also infers that managerial or strategic-led designs for sustainability are only part of the solution.

The involvement of non-managerial employees using both internal and external information 'in situ' to make sustainable decisions in daily tasks is a key contribution of Johnstone's (2019) framework (see also Heggen et al., 2018). Proposing sustainable change as a combination of top-down and bottom-up exchange process between employees, moves move away from the perception of accounting systems as uncontested means to achieve organisational outcomes (see Roberts \& Scapens, 1985). However, to date, control originating at the operational level remains under-researched or rarely explicated (see Coyte, 2019). This is because the general employee is often treated as part of a homogeneous group of corporate actors to be controlled through formalised system design in extant intra-organisational MCS frameworks.

While indeed there may be some individual employees who work best operationally when explicitly directed in terms of the working process and do not deviate from organisational-led controls, there may also be others who prefer autonomy and independence to meet goals or even are better qualified than management teams to help direct the design of future formalised controls. To this end, Johnstone (2019) further suggests that individual employee characteristics are important for knowing how to improve sustainability performance. Building on Wouters and Wilderom's 
(2008) earlier work, she describes these 'process characteristics' as: the experience and professionalism of the employee; the ability for the employee to experiment with working processes to improve practice; the employee's awareness of organisational roles and tasks (i.e. both the global and local transparencies); and, the employee's sustainability competence which is defined as the individual's ability to solve sustainability problems in situ based on forward thinking, problem solving and coping with uncertainties in daily working tasks (see Wals, 2010; de Haan, 2006).

Nevertheless, while Wouters and Wilderom (2008) emphasise process characteristics as the product of formalised system design (see also Coyte, 2019), Johnstone proposes that external factors also affect these 'personal' characteristics in terms of the operators' sustainability knowledge and experience. These experiences, in turn, affect the individual's working abilities to solve sustainability problems in situ and contribute to the (re)development process of the SCS. They may also lead to a concerted group effort to meet the expectations of organisational system design. This, consequently, contributes to the broader sustainability discourse as the responsibility of every member of society, not only a corporate or managerial issue (see Rinaldi, 2019), and responds to calls for more attention on the individual employee within sustainability control research (Ghosh et al., 2019).

Using the framework of sustainability control as an analytical tool in this study is considered important for the SME context given that SMEs have fewer resources and shorter chains of command, and everyone is expected to play a role in meeting sustainability aims (see Fassin, 2008; Stubblefield Loucks et al., 2010). This latter point also suggests that informal system design elements are important for environmental performance in terms of a participatory approach (see Pondeville et al., 2013). The framework furthermore emphasises the importance of understanding how individual behaviour is guided by both organisational and individual beliefs systems for improved sustainable performance. Here, the interrelationship between 'control over' (i.e. via the design of formalised systems by top management) and 'control in situ' (i.e. system use and (re)design by the individual system user) is proposed as useful given that it emphasises system design and use as a interrelated process wherein individuals of all levels are part of the solution. This builds on Coyte's (2019) work which finds that the compression of hierarchy is key for ensuring accountability throughout the organisation, as well as for stimulating employee communication and learning, among others. As an overview, Fig. 1 overviews the theoretical framework guiding this study. Particularly, it proposes an interrelationship between the orientation of management control for sustainability which is not purely hierarchical as previously studies tend to suggest.

\section{Method}

\subsection{Study background}

This study adopts a qualitative cross-case interview approach of eighteen SME representatives and seven auditors in the UK, Ireland and Sweden to explore how sustainability control is characterised and used in SMEs through the implementation 


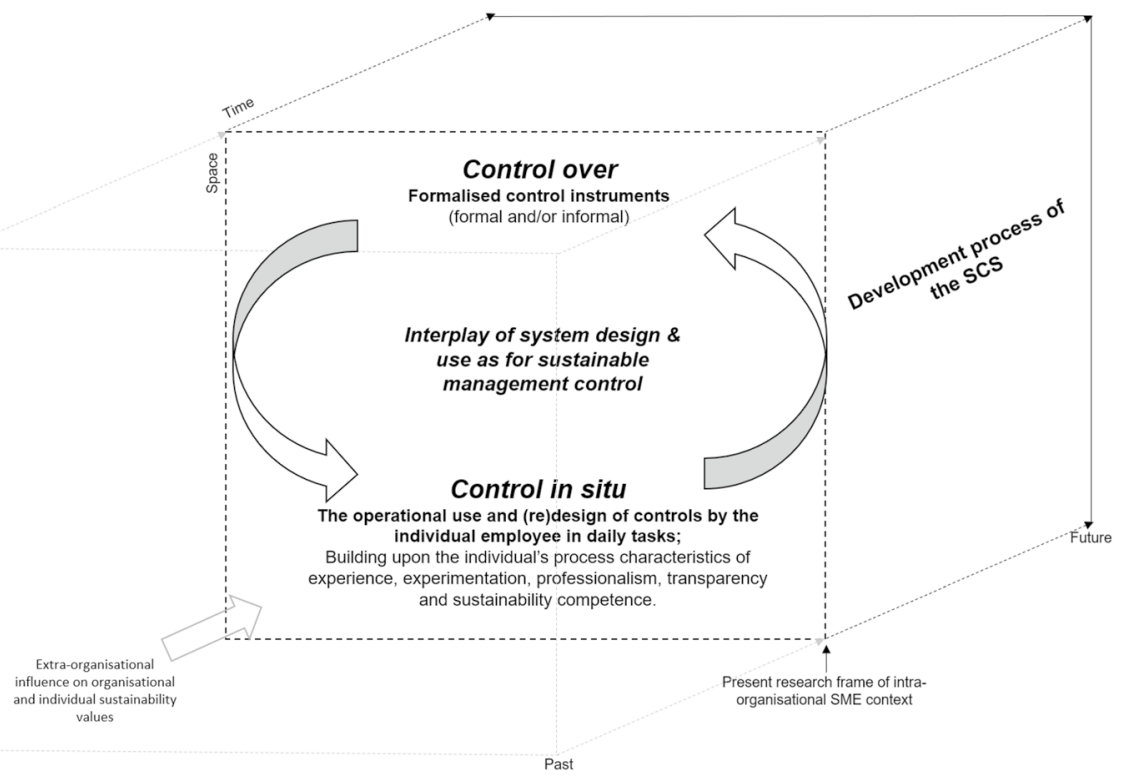

Fig. 1 Theoretical framework of sustainability control ( adapted from Johnstone, 2019)

of an EMS. ${ }^{4}$ Interviewing multiple professionals is considered useful to provide more informed theoretical perspectives on environmental management systems (EMS) and their implementation in practice (Boiral et al., 2018; Mazzi et al., 2016). These individuals arguably know the empirical context of —in this case-ISO 14001 implementation given that they work with this daily. Nevertheless, studies that incorporate the perspectives of different stakeholders in ISO 14001 implementation are rare (Boiral et al., 2018; Heras-Saizarbitoria \& Boiral, 2013).

The empirical context of this study regards SMEs as a 'sector'. SMEs are defined as having less than 250 employees or a turnover of equal to or less than 50 million euros (European Union Commission, 2003). SMEs are often presented as a distinct sector in extant EMS research (e.g. Graafland, 2018; Johnson, 2017; Witjes et al., 2017) which is not necessarily contingent on single country analyses (e.g. Graafland \& Smid, 2016; Johnstone \& Hallberg, 2020). Rather, this study assumes that SMEs have similar characteristics in terms of structure, ownership and environmental attitudes (see Perez-Sanchez et al., 2003; Stubblefield Loucks et al., 2010), regardless of the country of origin. Consequently, a cross-case interview approach of SMEs and ISO 14001 auditors operating in Northern Europe was adopted as a first step for defining how sustainability control is generally characterised and used in SMEs implementing an EMS.

\footnotetext{
${ }^{4}$ The choice of these countries primarily comes down to access issues and this study is not a crosscountry analysis.
} 
SMEs certified to ISO 14001 are explored in this study. Importantly, certification and standardisation are not the same thing; that is, an organisation can have an EMS in place yet chose not to have it certified. However, ISO 14001 certified SMEs are selected to guide this research for the following reasons.

First, ISO 14001 can be regarded as an empirical example of a standard which incites specific control-related issues within the firms that adopt it. As an international standard, it requires organisations to establish internal processes for environmental management, which may - or may not-be documented, to improve operational effectiveness and efficiency annually (ISO 14001: 2015). While some of these are mandatory (e.g. the Environmental Policy, compliance to external legislation and performance evaluation), others are merely recommendations. Yet, there is no 'framework' regarding how organisations must disclose the necessary information for meeting the standard. As such, flexibility is a condition built into ISO 14001 . Importantly, the latest version of ISO 14001 emphasises that the implemented EMS should be used as a means not an end for improving environmental performance outcomes annually.

Second, in accordance with Johnstone's (2019) framework of sustainability control which guides this research, ISO 14001 necessitates both employee (managerial and non-managerial) participation in the implementation process of the EMS, as well as asserts the strategic establishment of some formalised codified actions (e.g. through a Code of Conduct, documented procedures, KPIs etc.). Resultantly, the selection of ISO 14001 relates to the levels of the analytical framework as well as recent developments in the sustainability control literature which emphasise employee participation beyond managerial tiers (e.g. Johnstone, 2019; Sundin \& Brown, 2017; Won Kim \& Matsumura, 2017). This shifts the focus from the strategic design of sustainability controls by (top) managers to the sustainable management of processes to achieve improved environmental performance throughout the organisation levels. Particularly, ISO 14001 asserts that all employees are involved through their competence and awareness of the EMS and its associated processes and procedures (ISO 14001: 2015).

Third, ISO 14001 is the most popular reference standard which helps firms implement an EMS (see Boiral et al., 2018). This latter point was particularly useful given that it is often difficult to find SMEs that have an EMS in place from their websites and advertising materials. To this end, external third-party ISO 14001 auditors were first approached via email as intermediaries who served a liaison function for finding ISO 14001-certified SMEs. This was furthermore necessary due to confidentiality agreements between auditors and their clients.

Notwithstanding, given the design of this study is motivated through the analytical framework of sustainability control, it could be argued that ISO 14001 only covers the environmental dimension. While indeed sustainability is broader than the environment, the implementation of an EMS here is used as the context to explore sustainability control. Not only is the environment the foundation for many social and economic concerns, but environmental performance has also been suggested in previous SME-EMS research as multidimensional, including social, operational and financial elements that are not easy to separate in practice (see Johnstone, 2020b; Johnstone \& Hallsberg, 2020). Thus, the context of an EMS is considered a broader 
indicator of the design and use of sustainability control within SMEs which builds on an emerging stream of interest (e.g. Ghosh et al., 2019; Johnstone, 2020a).

\subsection{Data collection}

The main technique in this research was semi-structured interviews in person, online and by phone with those responsible for the implementation and evaluation/certification of an EMS in SMEs. This included both individuals within the SMEs, as well as the ISO 14001 auditors who served as the primary access channels for finding SMEs with an established EMS (namely, ISO 14001) in place.

Initial contact with the ISO 14001 auditors was through various channels. First, personal contact with an auditor in Sweden resulted in referrals to additional auditors in the UK. Second, contact was made through searching lists of auditors online and subsequently canvassing them by email and phone, asking them to participate in the study. In total, seven interviews were conducted with the ISO 14001 auditors. Not only did the auditor interviews function as access channels, but they also allowed for the triangulation of SME viewpoints with the auditors' perspective, as well as gaining deeper insight into the role of ISO 14001 for the implementation of an internal EMS. In this sense, the auditors' professional perspective and experience allowed further light to be shed on the implementation of an EMS in SMEs.

After the auditor interviews, various SMEs were contacted by the auditors themselves asking them to participate in this study. Upon agreement, the SMEs were thereafter referred directly to the researcher. Eighteen representatives from ISO 14001 certified SMEs agreed to be interviewed. These interviews were often directed to the person responsible for the documentation of the EMS within the SME, who had another formal role in addition to that of the primary contact person for ISO 14001 (see Table 1). While some may argue that speaking to those responsible for ISO 14001 in the SMEs may not give a comprehensive picture of the implementation of the EMS throughout the organisational levels, it was deemed appropriate for the purpose of this study. This is because the SMEs in this study generally had few employees (most SMEs had less than 50, with some with as few as four) and those responsible know the most about how it was implemented throughout the organisation, as well as who by. Moreover, given that this paper is analytically framed around the framework of sustainability control to gain a first-stage insight into how sustainability control is generally characterised in SMEs (see Johnstone, 2020a), and not Adler and Borys' (1996) enabling-coercive control framework, the 'employee perspective' of how control is perceived in situ is not the focus of this study. Therefore, although speaking to more employees at the operational level would have primarily served the latter aim and contributed to a more rounded understanding of the former, speaking to professionals in the implementation of the EMS within SMEs (both auditors and those responsible for the EMS) is still important (see Boiral et al., 2018; Mazzi et al., 2016).

In total, 25 semi-structured interviews were conducted, extending previous qualitative research in the area in terms of interview number (e.g. Granly \& Welo, 2014; Johnson, 2017). The recorded interviews took place between February 2018 and 
Table 1 Interview details

\begin{tabular}{|c|c|c|}
\hline First stage interviews & Second stage interviews & Position (and sector) \\
\hline Auditor A, UK & & Director \\
\hline Auditor B, UK & & Director of Quality Assurance and Compliance \\
\hline Auditor C, UK & & Quality Assurance Manager \\
\hline Auditor D, UK & & Lead Auditor \\
\hline Auditor E, Sweden & & Lead Auditor and Assessment Manager \\
\hline Auditor F, UK & & Auditor \\
\hline \multirow[t]{19}{*}{ Auditor G, UK } & & Environment and Energy Principal Assessor \\
\hline & SME 1, Ireland & Compliance Manager, Waste Management \\
\hline & SME 2 Ireland & Environmental Representative, Waste Management \\
\hline & SME 3, Ireland & Environmental Manager, Port Transport \\
\hline & SME, 4 UK & $\begin{array}{l}\text { Environment and Health and Safety Manager, Waste } \\
\text { Management }\end{array}$ \\
\hline & SME 5, Ireland & Facility Manager, Recycling \\
\hline & SME 6, UK & Management System Coordinator, Installation \\
\hline & SME 7, Sweden & Quality Manager, Healthcare \\
\hline & SME 8, Sweden & Traffic Manager, Bus Transport \\
\hline & SME 9, Sweden & Managing Director, Painting and Decorating \\
\hline & SME 10, Sweden & CEO, Brazing \\
\hline & SME 11, Sweden & Environment and Quality Manager, Signage \\
\hline & SME 12, Sweden & Vice-CEO, Plumbing and Welding \\
\hline & SME 13, Sweden & HR/Quality Manager, Painting and Decorating \\
\hline & SME 14, Sweden & Management System Coordinator, Construction \\
\hline & SME 15, Sweden & Technical Director, Construction \\
\hline & SME 16, Sweden & Marketing Manager, Solar Energy \\
\hline & SME 17, Sweden & $\begin{array}{l}\text { Sustainable Business Development and Strategist, } \\
\text { Biofuel Sales }\end{array}$ \\
\hline & SME 18, Sweden & Technical Manager, Transport \\
\hline
\end{tabular}

July 2019, lasting an average of $50 \mathrm{~min}$. These were then transcribed and entered into NVivo Version 11 in preparation for the analysis. The formal interviews with the SME representatives and external auditors were furthermore supplemented by informal conversations with the auditors on telephone and through email, as well as information from the SMEs' websites and personal correspondence with the ISO 14001 responsible in the SMEs. This additional material allowed for a better contextual understanding of how the EMS were implemented in the respective SMEs in terms of their business areas, clients and environmental impacts.

Although the interview process regarded two sequential stages (i.e. first the auditors, then the SMEs connected to each auditor), the interview questions for both the auditors and SME representatives were operationalised for the purpose of this 


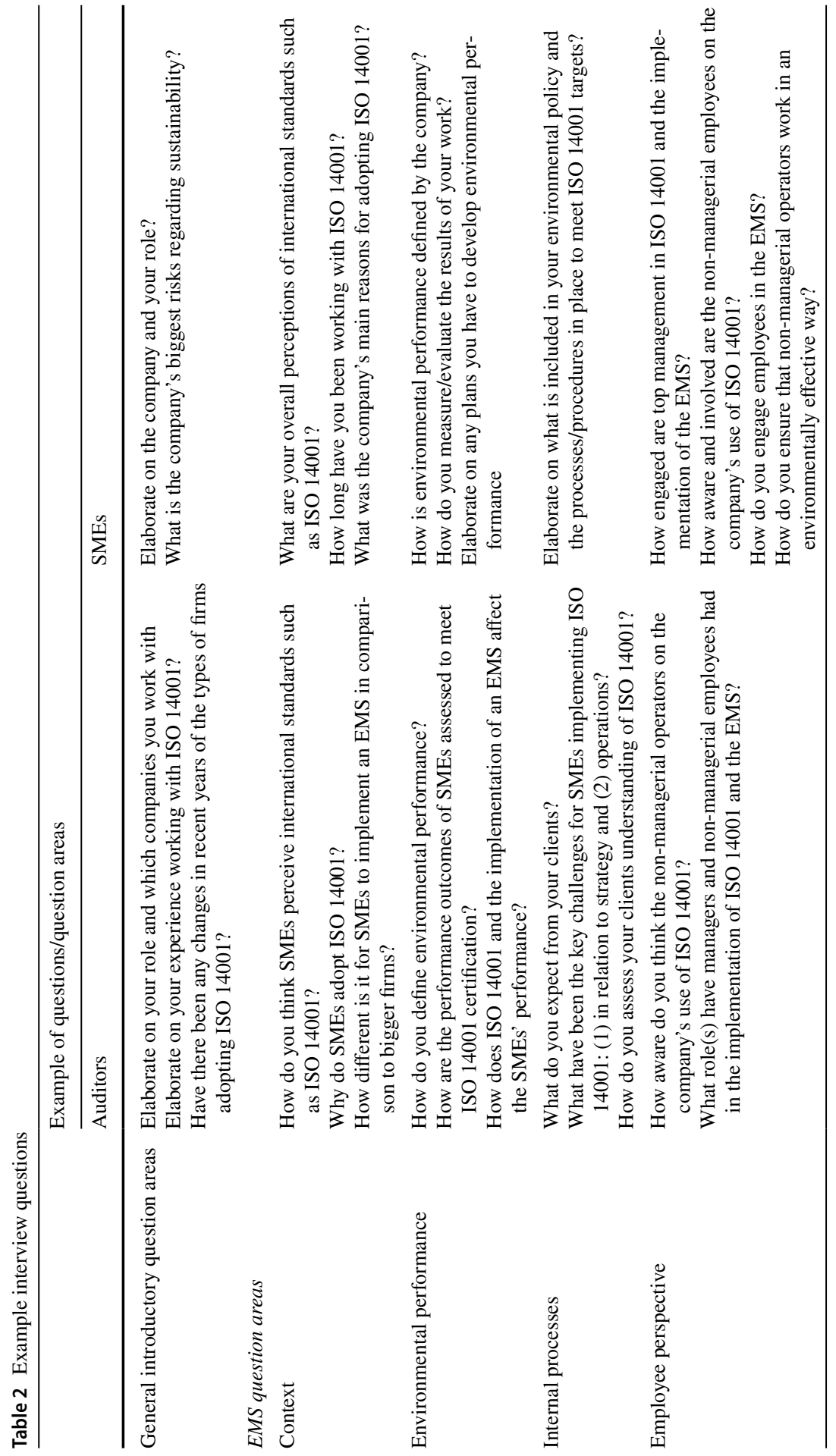




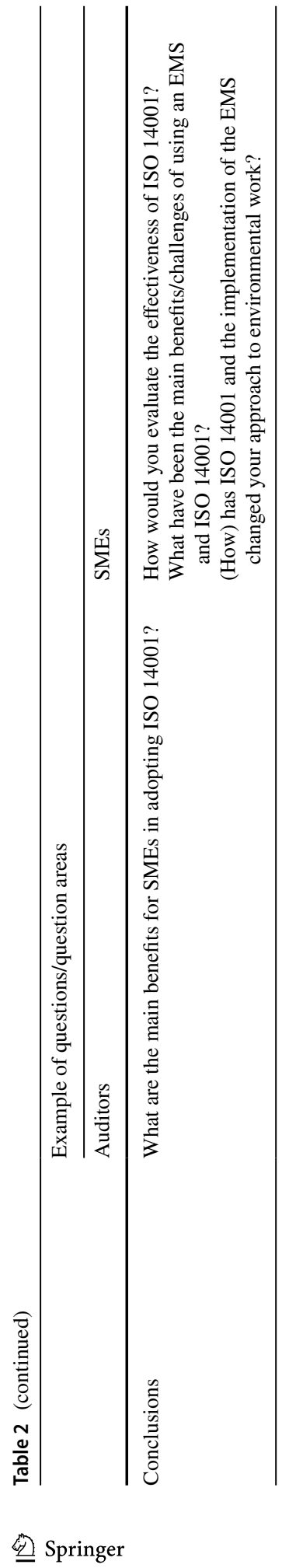


study around Johnstone's (2019) framework of sustainability control. ${ }^{5}$ Particularly, thematic questions which regarded the 'formalised' procedures put in place (e.g. internal processes and controls to meet improved environmental performance) were operationalised as control over, whereas questions on employee (managerial and non-managerial) involvement and understanding were operationalised as control in situ (see Table 2).

In order to establish the formalised control procedures put in place by the SMEs, the SME representatives and auditors were asked a series of broad questions regarding the operationalisation of environmental performance through the introduction of an EMS. Particularly, EMS are considered important for improving internal processes which subsequently benefit environmental performance. Therefore, the SME representatives were then asked to expand upon the processes put in place to improve environmental performance annually, as necessitated in ISO 14001. These were viewed as indicators of the controls implemented upon ISO 14001 adoption in relation to its annual performance cycle. On the one hand, organisational controls may be formal in nature, based on compliance, discrete performance goals, documented procedures and clear governance structures, among others. On the other, they may take a more ad hoc or responsive nature within the SMEs in terms of informal discussions between managerial and non-managerial employees, as well as autonomy and responsiveness at the operational level in daily working tasks. The findings of these questions aimed to capture the responses and provide a general overview of the formalised SCS design characteristics put in place by the SMEs to meet ISO 14001 through explicit examples which were orientated towards either formal or informal control aspects. Second, to understand how formalised controls are received, used and redeveloped in practice at the operational level which exists as the interface between organisational and individual sustainability beliefs systems (i.e. control in situ Johnstone, 2019), questions were orientated towards the 'employee' perspective.

Importantly, the auditors were asked to focus their responses on their SME clients given the nature of this study and any information or examples of larger firms were omitted in the analysis. Throughout the interviews, the interviewees were prompted to give examples. The discussions, however, were kept informal and the interviewees encouraged to interpret the questions by themselves where possible. This was deemed useful to tease out their responses in their own words, allowing patterns to emerge inductively regarding the broader characteristics of control via explicit examples based on their own experiences of EMS implementation.

\subsection{Data analysis}

The analytical procedure involved the following stages which informed the structure of the findings. Notably, the findings are grouped around the analytical levels of 'control over' and 'control in situ' wherein various higher-order themes are drawn

\footnotetext{
5 Note that this study is part of a broader project on EMS in SMEs. Therefore, not all question areas of the interviews are listed in Table 2. This is because they are not relevant for the purpose of this paper.
} 
out, serving as the basis for the following discussion. Notwithstanding, it is important to emphasise that although separated analytically through the study design, the analytical levels interact to produce sustainable performance outcomes and based on Johnstone's (2019) argumentation, are difficult to separate in practice.

First, interview fragments relating to the framework of sustainability control were coded in NVivo, specifically in terms of the formalised design characteristics (i.e. control over) and system use and (re)design by operators (i.e. control in situ). Given that the areas of system design and use constitute interaction, the fragments were separated in terms of their explicit referral to controls designed to implement the EMS (i.e. control over), and the use of said controls at the operational level for sustainable performance. Particularly, the roles of managerial and non-managerial employees in relation to sustainability control were analysed in relation to enacting the formalised controls in situ. ${ }^{6}$ This meant that sometimes 'new' formalised controls were brought up in the responses explicitly coded as system use. It furthermore builds upon the explicit clauses in ISO 14001 which are motivated towards building employee involvement at the operational level in terms of their roles, commitment and responsibility for the management of the system.

Second, the analytical procedure for elaborating on control in situ then involved separating the interview fragments based on their orientation towards how managers (particularly top management) as employees or non-managerial employees helped in the implementation process of the EMS and worked daily with the EMS. This reflects the organisational levels embedded into the specific ISO 14001 clauses that focus on managers or leaders (Clause 5) and non-managerial (Clause 7) operators as distinct categories for the EMS implementation process. Particularly, an understanding of how operators beyond managerial tiers are involved in the design and use of the EMS was deemed useful to capture the characteristics of individual employees that help improve environmental management processes (i.e. the process characteristics in terms of their experience, professionalism, experimentation ability, knowledge and sustainability competence see Johnstone, 2019). Here, engagement through action was tied to the individual's process characteristics in situ. Nevertheless, the boundaries between managerial and non-managerial action were blurred for some SMEs in this study that had few employees. In such SMEs, the managers were not only involved in the formal design of controls to improve environmental performance, but they were also responsible for meeting environmental targets operationally through daily working tasks.

Third, managerial and non-managerial fragments were further coded into a higher order theme which can broadly be regarded as 'engagement'. From the 'managerial' stance, engagement was framed around 'buy-in' which had performance-related and cultural effects both within and beyond the SME boundaries. Meanwhile, for

\footnotetext{
${ }^{6}$ As a reminder, most of the SME interviewees were not necessarily top managers in many of the SMEs (see Table 1); rather, they were those made responsible (by management) for the EMS implementation process. In this sense, their positions were often tied to the middle-managerial level and one can arguably state a more reliable perspective on the role of managers (top and middle) and non-managers (operators) in EMS implementation.
} 
the employee side, 'getting employees onboard' stood out as important for the EMS implementation process to improve environmental performance through both formal and informal design features, as well as the interaction between organisational and individual beliefs systems for each thematic grouping.

Regarding the latter point, fragments were coded in terms of control in situ that reflected individual sustainability values that may-or may have not been-borne from environmental management-or the EMS — in the SME. This coding process meant that in addition to the specific interview questions constructed to address the analytical levels of control over and control in situ from formalised organisational controls, the role of individual beliefs or values also emerged from the data as intertwined with formalised controls throughout the higher order themes which are: employee engagement through (a) environmental knowledge and experience, (b) passionate interests, (c) performance measures and (d) compliance. These higherorder themes allowed for a more detailed assessment of how the EMS is designed and used in practice in situ as a combination of organisational and individual beliefs systems. It also allowed for a better understanding of the characteristics of control in terms of the behavioural consequences of system design, as well as the potential of operators to contribute to system (re)design through their own individual process characteristics stemming from both the internal and external firm context.

As a final step, the findings were then consolidated into a summative table which connected the analytical levels in terms of Johnstone's (2019) framework of sustainability control for the studied SMEs. This provided an overview of how employee behaviour in situ follows from both the formalised design features of the SCS andas an extension to previous sustainability control research-also from the individual's external experiences, values and beliefs about sustainability. This summative table concluded the analysis by framing the findings in terms of how employees are facilitated to perform 'sustainably' in their daily working tasks within the empirical context of ISO 14001-certified SMEs as the empirical context. This facilitation is evidenced and discussed in terms of the broad characteristic type and use of the control which are considered in the framework of sustainability control, rather than in terms of its interaction effects and discrete control typologies; thus, allowing some conclusions to be drawn.

Note that although the SMEs in this research operate in different markets and sectors (see Table 1), they all have an EMS in place and have chosen to have it certified by an independent third-party auditor to ISO 14001. While the responses may highlight contextual phenomena in terms of operations and legislative context, the overall broad characteristics of sustainability control are viewed as comparable due to the above-mentioned characteristics, as well as the SMEs' decision to adopt ISO 14001 for environmental management. Specifically, an analysis of the findings for this study, which addresses the broad characteristic type and use of control in SMEs implementing an EMS, did not yield any significant differences in terms of SME 


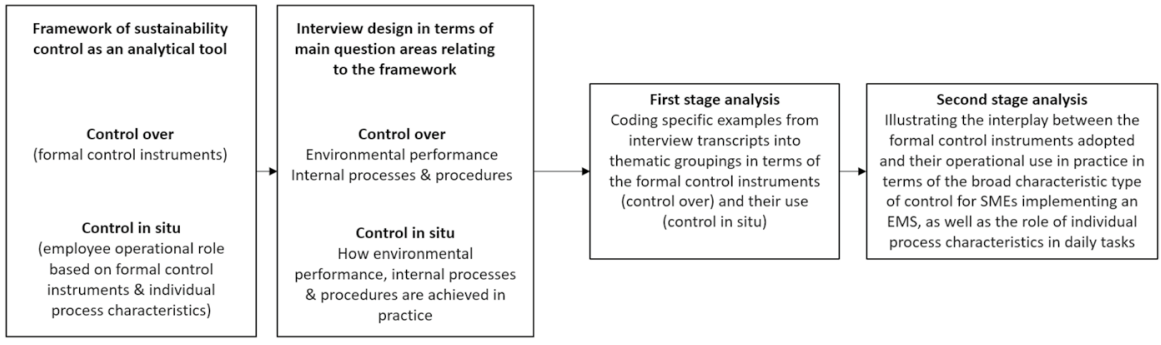

Fig. 2 Interview design and analytical procedure

business area or size. ${ }^{7}$ This meant that although some of the SMEs had only recently adopted ISO 14001, the findings from these firms were comparable with those that had had ISO 14001 in operation for longer. Moreover, an analysis of the auditors' responses did not provide alternative opinions in terms of the broad type and use of control in SMEs implementing an EMS through ISO 14001. In this sense, the auditor interviews only served to triangulate the data.

\subsection{Overview}

Figure 2 summarises the data collection and analytical process in relation to the framework of sustainability control which guides this research as an analytical tool (Johnstone, 2019).

\section{Findings}

As explained in the method, the structure of the findings section is reflective of the analytical levels in Johnstone's (2019) framework of sustainability control which guides this research. Although these levels are present as distinct analytically, they interact to improve environmental performance through, in this case, the implementation of an EMS. Moreover, while control over and control in situ are framed 'within' the intra-organisational boundaries, operator action is connected to both organisational beliefs systems and values (i.e. intra-organisational systems), as well as individual ones regarding the sustainability as an extra-organisational discourse. In this sense, external factors are embedded into the findings through the analytical framework which recognises that management control for sustainability is not only the product of internally designed systems. This is furthered by the professional opinion of external actors (i.e. the ISO 14001 auditors) who understand how environmental management is achieved through their assessment of the internal

\footnotetext{
7 That is not to say that differences were not noted in other papers resulting from this research project, for example, in terms of ISO 14001 adoption reasons (Johnstone \& Hallsberg, 2020) and its performance effects (Johnstone, 2020b).
} 
operations within the SMEs which provides feedback for further system improvements as part of the annual performance cycle.

\subsection{Control over}

Control over regards the formal design elements put in place by the SMEs to meet ISO 14001 annually by making performance improvements. These are formalised in the sense that they are officially considered in the construction of the internal system of controls to improve performance outcomes yet can involve formal and informal types of controls to guide action in situ.

The findings reveal a tension between the formalised design elements through EMS implementation and the ISO 14001 certification process for the SME context. Auditor C suggests that SMEs are perhaps less guided by formal controls than larger businesses:

[...] it is easier for a smaller business to make changes because they are closer to [...] the environmental risks and opportunities... and I think that they should be able to achieve a shorter implementation time than you would typically see in a larger firm; [...] when a firm gets to a certain size, it has to have in place processes and have a disciplined approach to management-Auditor C.

Particularly, there is the perception that the SME context is less likely to be at odds with latest revisions of the standard which propose less reliance on documented procedures and processes (i.e. formal controls) and more on environmental management as internalised within the minds of all employees as guiding discussion (i.e. informal controls). This revision embraces a flexible and participatory approach in the EMS, which emphasises teamwork, awareness and communication, among others, which do not have to be formally documented (see Sects. 5 and 7, ISO 14001: 2015).

Nevertheless, responses from the SME representatives suggest that rather than being characterised by informal control which is increasingly promoted by the latest version of ISO 14001 that requires less documented procedures, the formalised control instruments adopted to achieve certification are primarily orientated towards quantifiable measures in terms of discrete targets and controls regarding resource efficiency and environmental impacts. For example, SME 1 commented on the need to "set up objectives in relation to impacts and aspects, and then work towards them". Moreover, SME 8 highlighted the periodic (re)design of such targets to achieve annual improvements which is embedded into the ISO 14001 certification process.

Beyond the formal design of targets and measures to meet them, most SMEs provided some information of the operationalisation of said targets in terms of process efficiencies connected to waste management or carbon emissions. For example, there was the desire by multiple SMEs' to "make the most of the resources [...]; whether it is reusing as much as we can or mimimising as much as we can to mimimise the environmental impact" (SME 2). Moreover, controlling for such 'tangible' 
impacts were often presented as tied to the perceived need to "keep logs and statistics" (SME 17).

Meanwhile, only two SMEs presented a more abstract perspective on the operationalisation of environmental management through EMS implementation in terms of performance improvements. SME 10 commented on organisational accountability to nature and future generations. Further, SME 4 highlighted that EMS implementation is tied into working with "likeminded people" and "community engagement" which looks at performance "not only in terms of utility use". Arguably, these few responses illustrate a more characteristically informal approach to control and reflect the latest revisions of the standard.

Attempts to quantify measures and construct controls to meet environmental aims indicates compliance within a framework of specific objectives (i.e. the perception of ISO 14001 requirements for the implementation of an EMS by the interviewed SMEs). There is the general perceived need to have documented procedures and discrete objectives for many clauses tied to the ISO 14001 standard; consequently resulting in the design of primarily formal controls by the SMEs in this study.

Particularly, the compliance focus remains on the external dimensions explicated in ISO 14001 which attach importance to a stakeholder concerns and legislation that should be formally documented as part of the ISO 14001 certification process ${ }^{8}$ :

Customer complaints. [Are] there any incoming complaints of an environmental nature and how do we manage them through corrective preventative action? And, legal compliance-are we compliant with all our licences and permits designed to protect the environment?-SME 4

The external operating context of the SME is imperative for the design of internal environmental targets. Nevertheless, an assessment of incoming materials (i.e. raw materials as inputs which are essential for operations) are rarely explicated by the SMEs in terms of environmental performance management. Rather, the focus is on what is going out of the SMEs in terms of emissions and waste. This point is also recognised by Auditor E who comments that "not only SMEs, but all companies [...] are not thinking outside the box [...] they need to look at the other end. What is coming into the company?".

Such findings suggests that rather than promoting a cradle-to-cradle philosophy of environmental management in terms of inputs, outputs and afterlife, SMEs primarily follow ISO 14001 requirements tied to performance in terms of "controllable', intra-organisational outputs. It also implies that ISO 14001 may be considered as a higher-level compliance mechanism itself, rather than the establishment of an EMS which is flexible to the SME in case. Here, the SMEs adhere to ISO 14001 in terms of what they perceive to be formally required through its clauses, namely in terms of the compliance obligations, and risks and opportunities. This primarily manifests itself for the SMEs by incorporating external consultants' concerns

\footnotetext{
${ }^{8}$ For example, Clause 4 and 6 emphasise that the scope of the EMS, the risks and opportunities, compliance obligations, environmental objectives and the processes needed for general plans of action should be formally documented by the organisation (ISO 14001: 2015).
} 
to improve firm-level processes and resultant outputs. While, on the one hand, this compliance or procedural driven type of control tied to the ISO 14001 certification process may be good for improving the internal EMS and environmental performance through the establishment of discrete 'lower level' controls within the organisation, it may also arguably stifle innovation and reduce environmental thinking to within the box as indicated.

Although most firms signal a preoccupation with the formalised coercive controls and environmental management asserted by ISO 14001, some firms do recognise externalities in terms of the broader sustainability discourse beyond the firm. Particularly, extra-organisational temporality is signalled as strategically important for future environmental performance effects: "[It is important] to be responsible for what we use and what we give back to nature over time" (SME 9). Arguably, this relates both firm inputs and outputs, as well as adds a temporal scope. Notwithstanding, this temporality is not explicit in ISO 14001; rather it reflects broader societal attitudes towards sustainability. It may also be indicative of the guiding values of the SMEs' culture which condition its approach to designing its controls.

It appears that the environmental impact of operations (i.e. as outputs) is more important for most SMEs in this study than a consideration of environmental inputs into the formalised system design process. Although these initial findings do not say much about the actual use of control, they suggest that the formalised control instruments adopted for improved environmental management focus more on formal policies, processes and procedures, which are tied to the (perceived) requirements of ISO 14001 by the SMEs. Less examples are given of the flexible processes that may also be undertaken at the strategic level through the implementation of an EMS in terms of the follow up and/or communication of environmental processes within the SMEs through controls that are characteristically informal in character. That being said, elements of a broader accountability perspective were indicated by two of the SMEs representatives in this study who recognise their duty to society and future generations through the EMS implementation process.

Overall, environmental management for the SMEs in this study appears primarily guided by the (perceived) 'word of the ISO 14001 standard'-or rather, what can be regarded as traditional assumptions made on the standardisation/certification process by the SMEs or the external consultants hired by them to help in the EMS implementation process. This means that the design of formalised controls is mainly based on the establishment of organisational wide documented procedures and discrete objectives for the SMEs which they perceive as necessary to meet accreditation, as well as 'control' given that the bigger the SME becomes, the "less things can be relied upon by individuals" (SME 1). However, the most recent version of ISO 14001 asserts responsibility for environmental management not only to the organisation, but also to individuals and groups of individuals therein. It also reduces the need for formal documented processes, policies or procedures, and aims to promote-as Auditor D comments_environmental management thinking as something increasingly embodied by employees within the organisation who understand their role and part in the management system. This means that rather than following codified rules or procedures (or a tick-box exercise), the latest version proposes a more flexible approach to environmental management characterised by responsiveness 
and autonomy where environmental thinking is built into the employees' individual competence base, in addition to the areas which are required to be formally documented controls as per the standard's clauses:

In the new standard [i.e. ISO 14001: 2015 version], there is very little that actually needs to be documented. [...] To me, it is all about giving people the skills to be able to do it themselves [...]. And, that is where I find that a lot of small businesses are struggling, they have got systems, but they are not suited to what they are doing, and a one-size-fits-all system does not work-Auditor $G$

This suggests that even though the latest version requires very little explicit procedures and policies to be formally designed by the organisation, the degree to which SMEs use communication and support structures for improved environmental management, which build on an individual accountability perspective (see Sects. 5 and 7) and are informal in character, is limited in the responses explicitly referring to control over in this study.

\subsection{Control in situ}

While the analytical level of control over relates to the formalised design elements put in place to meet ISO 14001 certification, control in situ exists at the operational level and recognises the importance of individual process characteristics beyond managerial tiers. Notwithstanding, given that owner-managers in SMEs are often not only responsible for designing performance goals through EMS implementation (i.e. control over), but also responsible for meeting said goals operationally (i.e. control in situ), it is important to look at both managerial and non-managerial engagement as two sub-categories of analysis embedded within control in situ for the SME context. To this end, the following sections present control in situ in terms of the roles and actions undertaken by employees (managers and non-managers respectively) in their daily tasks to improve environmental performance. Here, sometimes 'new' formalised controls emerged from the analysis in terms of how daily actions improve environmental performance in situ.

\subsubsection{Managerial engagement in situ}

ISO 14001 positions the role of top managers as providing information on the EMS, supporting employees, as well as directing and monitoring progress (see Clause 5 'Leadership' ISO 14001: 2015). Here, managers are designated the ultimate responsibility for 'management' (control) of the EMS, even if it is normally key individuals - often in middle managerial roles-who are assigned the role of maintaining the system. ${ }^{9}$ Generally, the managerial role implied from

\footnotetext{
9 The role of top management embedded within Clause 5 of ISO 14001: 2015 for the implementation of an EMS shares parallels with definitions of sustainability control in terms of communicating sustainability objectives and monitoring progress to meeting such objectives (e.g. Johnstone, 2019; Wijethilake et al., 2018).
} 
the ISO 14001 leadership clause can be considered from a typical management control stance where subordinates are ultimately the subjects of control through system design. Nevertheless, the latest version of ISO 14001 additionally extends the role of managers as system designers and/or controllers to active participants in meeting environmental performance targets:

... management can't delegate the responsibility for the management system to someone else... they have to take responsibility. They can delegate the work or the actions that would be done, but they have to follow everything up and make sure that the person that they have delegated it to, has done what that person should do.-Auditor E

This responsibility or accountability perspective implies that the internal design of environmental management controls by top management is not enough in itself to meet ISO 14001 requirements. It suggests that responsibility for progress is a concerted team effort and that managers must be engaged in the EMS (re)development process in terms of operational actions. Here, there is the subtle inference that a successful EMS is contingent on managers as both designers and users of internal environmental management controls to improve performance:

I [as marketing manager and ISO responsible] am no more important than them [the non-managerial employees] because I am in the process of certification. This is something we do together; it's just that I sit on the audit and keep the threads, but we all have to contribute-SME 16

For SMEs, this is arguably even more important given that managers often have additional operational roles.

It appears that management engagement-or 'buy in'-is important for two, interrelated reasons. First, for the construction and monitoring of discrete performance-related goals; i.e. a conventional management control function. Second, to set the tone of the organisation's culture through leading by example. While both performance management and leadership style infer hierarchical system design in terms of control from the top, leading by example may also result in collaboration and responsiveness at the operational level. Here, various SMEs highlight the importance of managers and non-managers working together to establish environmental goals, as well establishing as the broader organisational values founded upon interpersonal relationships and a collaborative culture:

I think that [managers] talking about values is the most important thing... everything about how we treat our co-workers, customer relations, environmental relations... Discuss why it is important and if somebody else has another point, we discuss that, and if I [the manager] am wrong, I am wrong... it is no big deal. We try to get a common view of everything that concerns work. [...] I think they [the employees] know that in our company, we take [environmental] responsibility seriously-SME 9

Managerial engagement is additionally important to set the tone of the organisation's culture not only internally, but also externally: 
[...] If we fall on a compliance issue or by having poor public opinion, it can have a knock-on effect like 'they don't do what they should do right so can we trust them?' Credibility is very important to us. You will actually find my father [company owner] come out and pick-up litter. And, even further than that, [...] the business is shut on [a national holiday], to get the community to come out and pick-up litter across the city and county [...] so we actually get our entire staff out that day, like a team day, and send them off to pick up litter and bring it back. It is important, it is not just talk and effort-SME 1.

This latter example suggests that leading by example is not only important for establishing organisational beliefs and values, but that these environmental values can also translate into the SME's local communities.

Although most SME representatives present a positive picture of top management's role and engagement in the EMS, more critical perspectives are also evident. Some suggest that not all management teams or individual managers genuinely value the role of an EMS certified to ISO 14001 for improving both environmental and financial performance. In this sense, involvement in the EMS is not indicative of true engagement; rather, involvement is tied to the necessity of ISO 14001 certification. In this sense, it is ISO 14001 compliance for certification driving managerial 'engagement'. For example, there is the suggestion that top management are "reluctantly engaged" (SME 15) and only involved because they were told they had to be by, for example, external consultants, auditors or the employees who were previously delegated responsibility for ISO 14001 before the 2015 changes (i.e. the changes that assert managerial responsibility for the EMS). Moreover, there is also the viewpoint that managerial involvement resides at a superficial level. In this sense, there was the suggestion that top management would not be able to detail, for example, the corporate environmental aspects and are merely 'informed' on progress by those responsible for the EMS.

Even though a few of the SME representatives highlight more critical stances on managerial engagement, the general opinion by those interviewed is that managers (particularly top management) are becoming more committed to the EMS through ISO 14001 adoption. Particularly, there is recognition of both the substantive performance benefits realised through improvements in process efficiency and working procedures which may be the result of embedment in a wider supply chain, in addition to the symbolic performance benefits associated with ISO 14001 certification. ${ }^{10}$ These are embedded not only within the initial decision to adopt ISO 14001 by top management in the SMEs, but also its ongoing application and clauses which improve environmental performance throughout the supply chain. Nevertheless, Auditor $\mathrm{G}$ also suggests that increasingly, managerial engagement may also come down to explicit changes in the standard (i.e. ISO 14001: 2015):

\footnotetext{
10 The intent of this paper is not to analyse ISO 14001 adoption reasons and performance outcomes in SMEs; see Johnstone and Hallsberg (2020) for a more detailed discussion on the interrelationship between substantive and symbolic performance effects of ISO 14001 in SMEs.
} 
The old standard talked about commitment; the new standard has replaced that with leadership. Now, if you were to ask me the difference between commitment and leadership, it is the difference between reactive and proactive. A leader is much more proactive, maybe commitment could just be the managing director saying 'yeah, I've signed the policy, I am committed to this, just get on with it'. Whereas a leader actually inspires people and leads at the front by example. And, that is where the new standard sets itself apart. So, this leadership clause is all about the senior management within the business creating the right culture to move the business forward. It is again about creating this proactive culture within the business.

\subsubsection{Non-managerial employee engagement in situ}

Evidently, there appears to be varying levels of managerial (particularly top management) engagement as perceived by those responsible for ISO 14001 in the interviewed SMEs. Commonly, middle managers are put forward as those responsible for EMS implementation through their role and positions. Meanwhile, various SMEs indicate "great resistance in getting employees on board" (SME 15); a point which echoed by various auditors who present non-managerial employees as "not knowing very much about ISO 14001" (Auditor D):

They [the non-managerial operators] don't think about the standard at all. [...] They can't pinpoint in the work they do what is linked to the standard's goals... or the company's rules. But, if you go to the bosses and the people that work in the offices and so on [...] I think that they can more specifically tell that this is because of the standard-SME 7

Such viewpoints infer a disconnect between the formal strategic policy of ISO 14001 adoption in SMEs, and what that means operationally. Particularly, it indicates that knowledge of ISO 14001 per se does not transcend organisational levels to the extent that it should, and that operational action in situ is not framed from an ISO-stance. This is not to say that employees are not working towards environmental performance improvements, but rather, that they are simply not aware of the ISO 14001 standard as driving the EMS. This suggests that some SME-managers are not fulfilling their internal obligation of communicating ISO 14001 internally, embedded into Clause 5 (ISO 14001: 2015) which requires all employees to be aware of the EMS and its role in daily operational practice.

Nevertheless, a more detailed analysis of the roles, commitment and responsibility of non-managerial operators for the EMS suggests that there are different levels of engagement which can be drawn out at the operational level. Specifically, there appears to be proactive strategies within the SMEs tied to the formalised control instruments at the strategic level to engage non-managerial operators in situ. These can be framed loosely in terms of the extrinsic and intrinsic motivations of individual employees. Notably, while the thematic groupings of employee engagement in situ are presented in discrete sub-sections, an element of overlap is recognised in 
terms of the formalisation approach through system design, as well as through the specific types of controls illustrated under each thematic grouping. ${ }^{11}$

\subsubsection{Non-managerial engagement through environmental knowledge and expe-}

riences Various responses suggest that non-managerial SME employees can be engaged in environmental management at the operational level through their environmental knowledge and experiences as individual process characteristics. While this may be the result of training programmes formally embedded into system design, some SME operators were also presented as being more knowledgeable on their specific task roles and the operational processes than the management teams formally designing the controls. This implies that localised solutions to daily working tasks are not necessarily contingent on formal organisational processes and procedures, but that daily solutions and system responses also emerge from the bottom-up in the SME context. Here, system use is contingent on a general awareness of working processes at the task level, tied to the professional role of the employee for effective in situ repairs, in addition to the formalised control instruments designed at the strategic level. Nevertheless, non-managerial engagement in situ is presented as highly localised and resigned to the intra-organisational context:

The employees will say 'we reuse it, or otherwise it goes into the skip [a waste disposal container]'. But, 'do you know where the skip goes?' 'No'. 'Does the company that sell you the skip, do they know where it goes?' 'No'.-Auditor D

\subsubsection{Non-managerial engagement through building on employees' passionate} interests Non-managerial SME employees can also be engaged in environmental management at the operational level through — what can be termed-their passionate interests, which may include a passion about environmental sustainability or merely a passion to perform well or be rewarded. Thus, this thematic grouping elaborates on the use of both extrinsic and intrinsic motives to engage employees through their passionate interests at the operational level. Particularly, there is the common opinion by auditors that given resource constraints, the SMEs need to "tap into the enthusiasm of their staff"' (Auditor G):

If the business was clever, it would probably try and embrace their [the employees'] passion about the environment. Try to find some kind of objective to link the business with their passion-Auditor D

These interests are often not framed as the result of formalised control instruments and/or organisational values, but rather of personal ones which tend to originate from the extra-organisational context. For example, the internal audit, which is

\footnotetext{
11 Beyond these key themes, other minor themes were noted by individual SMEs in relation to employee engagement. For example, there was the viewpoint that employees could be engaged through teamwork, specifically collaboration across units for environmental management. Employee engagement was also presented as determined by the employee's age, with younger employees being more engaged in environmental management. Finally, firm size was also considered as being instrumental to engaging employees, with employee buy-in deemed easier in smaller firms.
} 
prerequisite for ISO 14001 certification, relies on individual employees volunteering to be part of the process with no explicit benefits tied to this involvement indicated by the SMEs in this study. Additionally, some SMEs offered examples of environmental projects established by non-managerial employees due to a personal interest in sustainability.

A few of the interviewed SME representatives suggested that employees 'volunteer' for the internal audit due to some sort of personal interest in the environmental management process. Nevertheless, most of the SMEs were not explicit in terms of how they 'found' such volunteers. This may indicate that perhaps the 'internal audit' role was assigned to employees and not through personal choice for most of the SMEs given that volunteering in the internal audit did not appear to provide any additional benefits for the volunteers, beyond extra work. Further, employee motivations for volunteering may well by tied to other desires in terms of promotion, rather than a true passion for environmental management.

More commonly, there were plentiful examples of what can be termed 'gamification techniques' used in situ by the SME representatives. Such techniques are used to motivate non-managerial employees by providing them with the necessary tools needed to achieve their job:

[W]e [...] departmentalise our business and our operations by empowering employees by the rules. So, if we give a driver his collection run for the day, we don't necessarily prescribe how to do it. We try to involve them [the drivers] in the process [...] and give them the tools and education to do that. [...] [W]ith that, we are trying to have everyone working on the same values and principles-SME 1

While these may be based on the employees' passionate interests about the environment, they are generally tied to making employees more enthusiastic to perform operationally through either explicit or implicit reward and compensation mechanisms. In this sense, the 'passion' is tied either to the performance competition or the outcome of said competition in terms of inciting a feeling within the employee. Another strategy noted is to subtly motivate weaker employees through positive feedback of the stronger ones:

We have understood that if you put all your energy into people who don't work too well [in terms of sustainability], they take a lot of energy because you have to look at them and tell them that they are doing wrong. But, if you instead focus on people who are doing a good job and put them higher up and give information to the rest of the group, then the people who aren't doing so well, they don't want to be there because they want to be in the good group. We focus more on the good ones-SME 13

Overall, the use of gamification techniques to incite or promote employees' engagement through building on 'passionate interests' emphasises the connection between organisational and individual values for improving environmental performance as well as sustainable competences: "Managing it [ISO 14001], and 
putting the proper processes in place feeds a culture... not just how you do environmental management, but also when you do other things" (SME 1).

4.2.2.3 Non-managerial engagement through explicit performance measures, controls and assessment Non-managerial SME employees can be engaged in environmental management at the operational level through explicit performance measures and controls. This builds on the previous example of positioning employees against one another, although more explicitly, to achieve daily tasks which is tied to 'tangible' rewards. For example, some SMEs use 'numbers' and computer simulations as gamification techniques:

[Our drivers] have a computer program in the bus that analyses all the results of their driving, which they get by email every month to see if they have improved their environmental driving skills. And, the results of that are linked to a higher salary every year [...] We also try to have competitions so the bus depots, the one that has the lowest cost in fuel, gets a barbeque night or they can go and have a social event, it is all the people in the depot who contribute to that-SME 7

The use of such explicit performance measures is to not only track performance, but to increase employee responsibility for environmental management:

We had a horrific amount of waste; throwing away paint especially and plaster. So, we made a big issue out of that and we showed [the non-managerial operators] all the numbers ... showed them what it could mean environmentally, and worldwide. We try to put it into the bigger perspective, as our part of the community. But, at the same time, [...] we also try to break it down into what it would mean for them... you know, 'if you actually use up these last four litres of paint that you have thrown away, if all of us did that, we could actually go on a two week trip next winter'. So, it is sort of trying to motivate them into taking care of these things. [...] Because some people in our organisation are pretty much under the opinion, you know, 'what the hell, it is not mine!' So, it's about trying to get everyone to talk 'responsibility'-SME 12

Rather than being based on the employees' passionate interests and cultural controls, this example forces employees to think about their actions in terms of compensation mechanisms where good behaviour is rewarded.

Performance can also be improved via the introduction of automated controls which - in contrast to the previous example - takes responsibility and autonomy away from non-managerial operators. For example, mechanised systems may be introduced to improve process efficiencies (SME 9), thus inferring tighter operational control. This highlights the tension between the implementation of technical controls as control instruments at the operational level which may demotivate employees by reducing autonomy while - at the same time-facilitating environmental process efficiencies. In this sense, such measures may concurrently negatively affect employee attitudes while positively facilitating daily tasks. 
While many of the SMEs perceive the need to quantify employee performance through measurable results, the auditors highlight that the assessment of employee involvement actually comes down to speaking to employees and asking them questions about their role in lay terms (i.e. not bound with the 'jargon' of ISO 14001). In this sense, operational action is assessed through the external audit process which aims to establish the intangible knowledge of operators working daily with the EMS. This assessment is bound within ISO 14001 and asserts that environmental management is contingent on individual knowledge and reflection at the operational level (Clause 7, ISO 14001: 2015), in addition to the explicit requirements of the standard (e.g. the Environmental Policy). And, if an employee comes out with a 'text-book' ISO answer, this would be met with scepticism (Auditor G). Indeed, while the auditors recognise that the assessment of employee involvement is ultimately a subjective process, they also assert that if the EMS associated with ISO 14001 is not truly building the environmental competences and awareness levels of employees at the operational level, they would be able to immediately tell. This would be presented as either an area for improvement or a non-conformity. Consequently, performance measures and their assessment can be both quantitative and qualitative in nature and assessment, even if the interviewed SMEs attach importance to the former in the design and use of formalised controls.

4.2.2.4 Non-managerial engagement through compliance Finally, non-managerial SME employees can be engaged in environmental management at the operational level through explicit compliance measures to improve environmental performance. While these compliance measures typically relate to corporate performance, compliance is also tied to industry, legislative or customer requirements for some of the SMEs in this study which set the permission scope to act.

Employee engagement operationally through compliance within the SMEs mainly involves formalised controls (i.e. official policies and procedures) to ensure consistency in working processes, among others:

Everyone is doing things the right way, the same way, consistently ... and that is the biggest thing that I see in it [ISO 14001]; that all your staff are all working to the same processes and procedures and no one is going off on a tangent doing their own thing... record-keeping is really good [...] everyone has a process that is easy to follow. [...] [We expect] compliance, that is the key thing. And by compliance I mean, if you are shown a procedure follow it, if you are shown a way of doing it, do it. Just don't deviate from the procedure! But, at the same time, [it is important that] if your employees find a better way of doing something that they will be able to say it-SME 4

Nevertheless, some SMEs present a tension between complying through procedures associated with ISO 14001 and environmental innovations:

I think if anything we were slightly more proactive on our challenges [in the past] than we are now, you don't really have as much time to do things like that. You are trying to just make sure that you are complying with all the different aspects, 


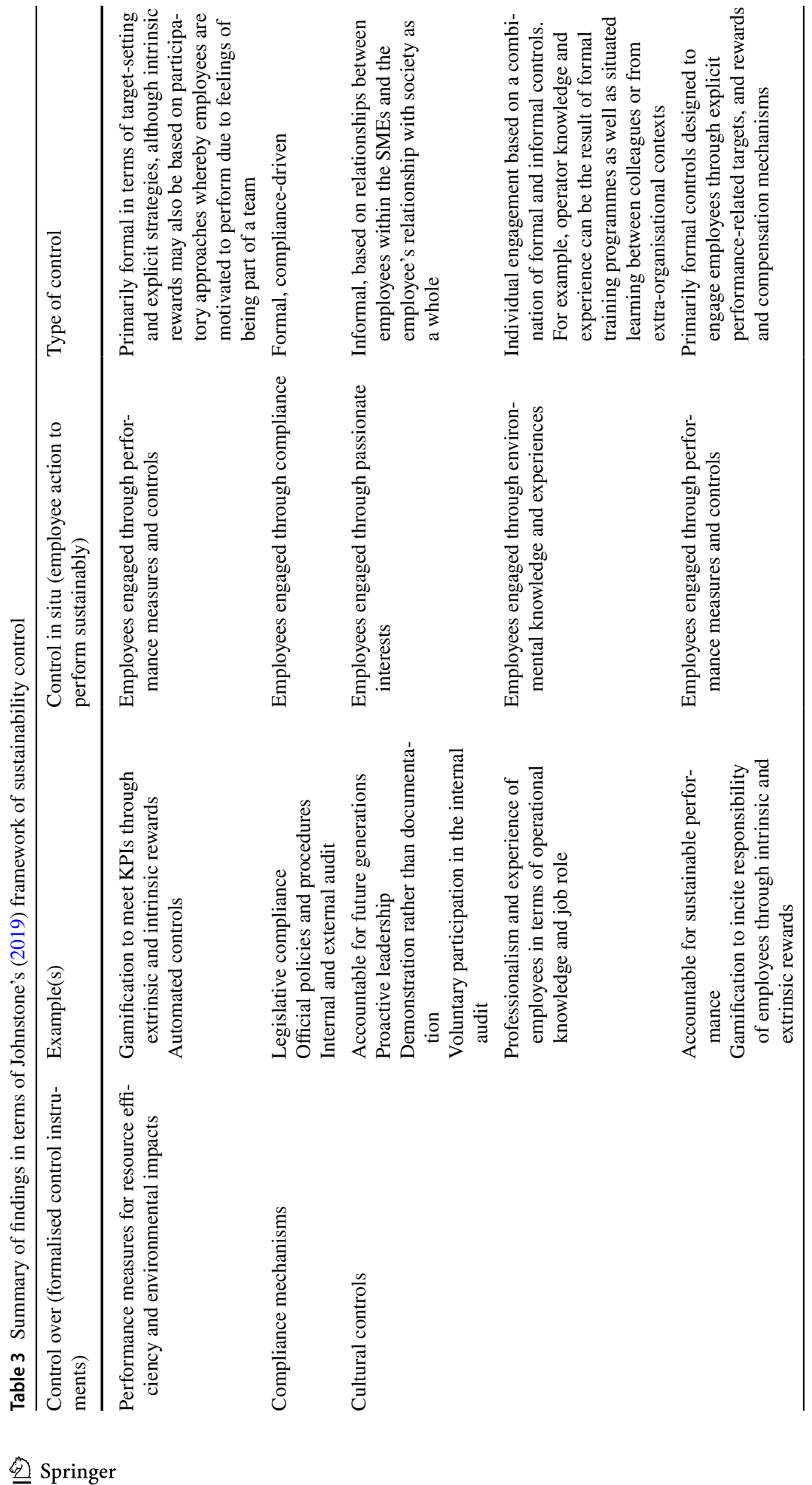




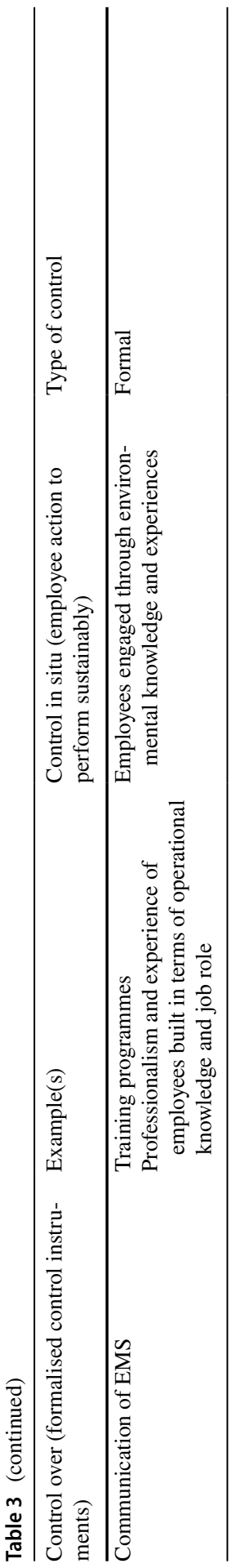


making sure that you are complying with your internal audits, making sure you are actually doing this, rather than actually going out and doing it-SME 3

This suggests that compliance through primarily formal controls can stifle creativity and waste resources. And, as previously mentioned, the SME responses overwhelmingly view compliance tied to ISO 14001 certification in terms of documentation and procedures to engage employees. However, as Auditor G comments "these days, you can get away with not having a single procedure [written down]” (Auditor G).

\subsection{Summative of the findings}

The summary of the findings involves combining the analytical levels from Johnstone's (2019) framework of sustainability control to offer some preliminary conclusions about the type and use of sustainability control in SMEs implementing an EMS certified to ISO 14001 (Table 3).

For control over, the study highlights key thematic areas in terms of performance measures, compliance mechanisms, cultural controls and EMS communication. The formalised design of these types of controls consequently affects control in situ (i.e. the operational use of said controls in practice) through engaging employees in the EMS. Nevertheless, the findings suggest that environmental engagement per se is not only an outcome of formalised system design at the operational level, but also embedded at the strategic level in terms of the organisational beliefs and values that guide the design of the formal control instruments. For a few of the SMEs in this study, the individual values and beliefs of owner-managers on environmental issues even appear to guide or condition sustainable behaviour throughout the organisation and beyond. Notwithstanding, these 'organisational' beliefs are complemented throughout the analytical levels in this study by individual ones that build on the non-managerial employee's sustainability values.

Overall, the these findings suggest that management control for sustainability, in essence, is not resigned within the SMEs' boundaries or managerial levels. This is because the individual's process characteristics, which affect behaviour or action to perform in daily tasks at both strategic and operational levels, may be a result of extraorganisational beliefs and value systems, in addition to those stemming from the formalised, strategically designed controls - whether formal or informal in character-to improve environmental management and performance. Thus, through its construction, Table 3 recognises that system design and use is contingent on extra-organisational factors that affect individual managerial and non-managerial approaches to daily working tasks. It can be viewed as an overview into the broad characteristic type of control in SMEs through EMS implementation.

\section{Discussion}

The findings of this study illustrate the interplay between the formalised control instruments adopted and their operational use in practice, analytical framed through Johnstone's (2019) framework of sustainability control. It appears that 
both the formalised control instruments designed for the implementation of an EMS in the SMEs and the operational use of these controls by in situ by employees are (generally) characteristically formal. Particularly, there is the perception that the establishment of formalised routines, documentation and procedures are key to meeting environmental performance targets operationally through ISO 14001 certification. Relatedly, it appears that non-managerial employees are primarily engaged in environmental management processes through formal control instruments tied to reward and compensation mechanisms (see also Sundin \& Brown, 2017). Nevertheless, ISO 14001 does not assert an overall procedurebased approach to control through its clauses. Rather, the latest version of the standard encourages companies to use it as a guideline to implement a flexible EMS, which is adaptable to the organisation in case. In this sense, rather than being a compliance mechanism or instrument of control as commonly asserted (see Brunsson \& Jacobsson, 2002; Ahrens \& Khalifa, 2015), ISO 14001 is moving towards flexible approaches which build on employee involvement and awareness throughout all levels, even though the SMEs in this study fail to recognise this.

For the SMEs in this study, ISO 14001 itself appears to serve as a compliance mechanism through its clauses, through which further operational control instruments are formally designed. This builds on Ahrens and Khalifa (2015) who assert that management controls arise from compliance frameworks such as ISO certifications, by implying that the ISO certification itself is the overarching control that guides the design and use of what can be regarded as 'lower-level' organisational controls (which are characteristically formal) in the SMEs. This characteristically formal approach to designing controls is ultimately founded upon the SMEs' interpretation of what is needed to meet said certification. Here, it is the ISO 14001 certification process that primarily drives the EMS and environmental behaviour.

The primarily formal nature of control in this study both confirms and contradicts previous research on EMS implementation in SMEs. On the one hand, it suggests that SMEs are systematic in their control attempts through increasingly formalised processes and procedures to meet environmental standards such as ISO 14001 (Granly \& Welo, 2014; Nawrocka, 2008). On the other hand, it contradicts the idea that environmental management in SMEs takes a more ad hoc, or informal character due to the unique features of this sector in terms of flatter organisational structures and decentralised power (see Halme \& Korpela, 2014). While cybernetic or diagnostic controls are commonplace in larger organisations to ensure subordinates are working towards sustainability goals (Crutzen et al., 2017), there is the assumption that informal control through interpersonal relationships guides behaviour or 'action' within smaller firms (see Bedford \& Malmi, 2015). However, for the SMEs in this study, the design and use of control is dominantly compliance-driven and procedure-based as perceived necessary to meet ISO 14001 certification. Notwithstanding, this study also reveals some more nuanced findings which thematically relate to the role of individuals within SMEs as instrumental for environmental performance. 


\subsection{The role of SME leaders in environmental management (control)}

Proactive leadership in the SME context for the implementation of an EMS is perceived as necessary in this study for both intra and extra-organisational environmental performance. Not only are the personal values of proactive leaders important for guiding environmental behaviour within the SME boundary as previous research suggests (see Spence, 2016; Stubblefield Loucks et al., 2010), but the individual values of proactive leaders can also filter out into local community projects (an insideout dimension). This suggests that SME leaders or owner-managers are not only 'responsible' for the design of formalised control instruments at the strategic level as commonly asserted in mainstream sustainability control studies of larger firms (e.g. Arjaliès \& Mundy, 2013; Durden, 2007; Gond et al., 2012), they are also expected to be actively involved in daily operations to improve environmental performance; performance which is not confined to intra-organisational boundary systems but embedded within a local community. In this sense, the boundaries between strategic and operational levels for sustainability control in SMEs are more nuanced than Johnstone's (2019) framework implies.

On the one hand, leaders are positioned both strategically and operationally within SMEs. This means that they are not only responsible for the design or approval of the formalised management controls for 'subordinates' to work with, but they also constitute part of the latter group of subordinates. Arguably, however, the term 'team' rather than 'subordinates' may be more appropriate for the SME context given that leading by example and teamwork were key themes drawn out from the findings. In this sense, proactive leaders in SMEs as part of the team are connected to an informal or participatory approach for environmental management which motivates other staff (see Crutzen et al., 2017; Tung et al., 2018; Laguir et al., 2019) and aligns with latest revisions in ISO 14001 (namely, Clause 5 'Leadership').

Notwithstanding, the true 'responsibility' of leaders appears obscured through this study. This is because it appears that environmental matters (in this case the ISO 14001 standardisation and certification process) are often entrusted to key individuals within the SMEs who can be regarded as sustainable entrepreneurs (see Schaltegger \& Wagner, 2008; Wagner \& Schaltegger, 2010). In this sense, although proactive leaders are recognised as increasingly important, the design of formalised controls to meet ISO 14001 certification are still often decoupled from the core through — in this case-individuals responsible for the EMS, and arguably for larger firms, through discrete sustainability departments as Gond et al. (2012) suggest. ${ }^{12}$ Arguably, this implies that sustainability control tends to run as a parallel process to the strategic aims of organisations, regardless of size.

Perhaps the most significant finding, however, is founded upon the relationship between organisational and individual values for-in this case-environmental

\footnotetext{
12 This also recognises limitations in assuming management accountants or controllers are important for implementing sustainability control within firms (see e.g. Harris et al., 2019). This is because such positions rarely feature in extant empirical research into sustainability control, and even less so in the SME context with fewer resources.
} 
performance and control. Specifically, the findings of this research support recent sustainability control research (e.g. Johnstone, 2019) by emphasising that a focus on the formalised organisational control instruments as the means to improve environmental performance paints a partial picture of the interaction between system design and use in practice. This moves beyond studies that ground sustainability control from a managerial perspective in terms of a strategic response to external stimuli (see e.g. Pondeville et al., 2013; Rodrigue et al., 2013). In accordance with Johnstone (2019), it appears that individual values (managerial and non-managerial) are also important for both the design of formalised controls and their use in situ. Particularly, the findings highlight a broader accountability perspective by some SME owner-managers for environmental management. This suggests that management control for sustainability regards the management of sustainable processes in situ (and even within a local community context), in addition to the management of subordinates through the formalised control system design.

\subsection{Engaging non-managerial employees in environmental management (control)}

As an extension to previous sustainability control research focusing on the behavioural outcomes of SCS design (e.g. Sundin \& Brown, 2017), the findings of this study suggest that operator engagement in environmental management may also be the result of individual values and experiences from the extra-organisational context, which guide approaches to the design of formalised controls and daily working tasks. This was illustrated through the summative findings wherein 'engagement' and the related 'engagement strategies' were evidenced through both analytical levels of system design and use (see Table 3), as well as encompassed both intra and extra-organisational orientations of motivations to act.

The sense that individual (non-managerial) employee action is guided not only by organisational values, but also personal ones for improved sustainable performance actions (Johnstone, 2019; see also Baker et al., 2018; Crutzen et al., 2017) (whether intrinsically or extrinsically) builds upon the accounting as a social practice literature (see e.g. Ahrens \& Chapman, 2007; Burns \& Scapens, 2000). ${ }^{13}$ It also extends previous research by suggesting that the characteristics of employees which allow for operational process improvements (e.g. experience, professionalism and sustainability competence, among others) are not only the product of formal control systems as previously suggested (Wouters \& Wilderom, 2008), but also something broader than the organisation; thus providing empirical support for Johnstone's (2019) framework of sustainable control. Here, individual experiences and sustainability values are presented as necessary for effective daily tasks in situ. Thus, individual process

\footnotetext{
13 This suggests that the characteristics of employees which allow for operational process improvements (e.g. experience, professionalism and sustainability competence, among others) are not only the product of formally designed control instruments as enabling and/or coercive as Wouters and Wilderom (2008) suggest, but are also due to the employees' personal values, beliefs and experiences that can also stem from the external firm context.
} 
characteristics are key for improved performance outcomes in the SMEs, even if knowledge of the ISO 14001 certification process for EMS implementation by non-managerial employees remains decoupled from operational action. While this 'decoupling' between the knowledge of organisational systems and local tasks may come as a surprise given that SMEs typically have shorter chains of command, it echoes Boiral (2007) who proposes that non-managerial operators only have a vague understanding of their role in relation to design and use of internal process controls for meeting ISO 14001 certification.

The focus on behavioural outcomes of employees in situ (i.e. the operational level) as not only the result of formalised system design is somewhat novel in the sustainability control literature stream. Arguably, such findings have implications for a broader responsibility or accountability perspective which could be used to frame future sustainability control research by marrying it with more critical literatures. This is because there is the inference in this study that employee engagement is built on a moral or personal discourse for environmental responsibility (see Messner, 2009), rather than purely the result of formalised controls and organisational belief systems; i.e. the reliance on organisational or management control structures as the means to improve sustainability performance (see also Wijethilake et al., 2018). That being said, the behaviour outcomes of system design for some non-managerial employees in the SMEs are clearly tied to explicit reward and compensation mechanisms, rather than some intrinsic concern for the environment. Thus, the interaction between personal and structural discourses of accountability (see Sinclair, 1995) through the design and use of the SCS for improved environmental management in SMEs is highlighted. This consequently responds to critical stances by recognising the inherent difficulty in separating the broader extra-organisational sustainability discourse in terms of personal values and beliefs, from organisational systems and practices. It also implies that sustainability 'management' is embedded and practiced within and throughout all organisational levels; not just the strategic levels which is often framed in terms of management strategies in response to legitimacy, contingency or stakeholder perspectives (e.g. Pondeville et al., 2013; Lisi, 2015; Wang et al., 2019). ${ }^{14}$

Building on that, the findings reveal some examples of strategies used within the SMEs to engage non-managerial employees in environmental management. Although this study is based on the SME context, these examples arguably contribute to the limited empirical focus on reward and compensation mechanisms in sustainability control research (see Crutzen et al., 2017; Soderstrom et al., 2017).

Gamification techniques, as formalised control instruments, build on intrinsic and extrinsic motivations to facilitate and engage (particularly non-managerial) SME employees in environmental operations are used by the SMEs in this study. These techniques are designed to bridge organisational value systems and the individual's operators process characteristics to improve environmental performance in situ. On the one hand, non-managerial operators in the SMEs are engaged in environmental

\footnotetext{
14 Note that overarching method theories are relatively scare in studies on environmental/sustainability control, with the domain theory of the sustainability control system often in focus.
} 
management through explicit performance measures and controls (i.e. externally orientated motivations). For example, employees can be rewarded for good environmental management with either tangible (e.g. monetary or material compensation mechanisms) or intangible (e.g. highlighting good performers to motivate the weaker ones) compensatory mechanisms. Here, the motivation is built through an engagement strategy tied to reward that incites some sort of passion in the employee to perform. On the other hand, non-managerial employees in SMEs are engaged through their own passionate interests about the environment (i.e. internally orientated motivations), which are reflective of a broader responsibility or accountability perspective. For example, some employees are motivated to work sustainably due to embodying certain values and beliefs about the sustainability discourse which are the result of extra-organisational influences (e.g. familiar concerns and a passionate interest about the environment see Johnstone \& Hallberg, 2020).

Arguably, extrinsic and intrinsic motivations exist together in guiding employee behaviour and it becomes difficult to separate them analytically and in practice. While previous research has found that the intrinsic motivations of staff are more important for driving corporate sustainability (Grubnic et al., 2015; Lueg \& Radlach, 2016; Rosanas \& Velilla, 2005), it is difficult to assess the true degree that intrinsic motivations affect individual employee behaviour in situ given their internally-orientated character. The findings of this study recognise that although intrinsic motivations are internally driven, there is potential for extrinsic management control instruments to be designed to promote the perceived intrinsic motivations of non-managerial employees in the SMEs (e.g. through training programmes designed at improving environmental knowledge or other intangible compensatory mechanisms as highlighted above). In this sense, feelings of individual responsibility for sustainable performance are not only the product of the extra-organisational context and individual values, but also of organisational values and designed management controls to further promote internal beliefs and values, in this case, regarding environmental sustainability. Thus, the findings of this study emphasise the difficulty in separating the motivational orientations when exploring how employees are facilitated to perform in situ as well as the formal and informal characteristic type of management controls designed to motivate employees. This furthermore supports Johnstone's (2019) claim of the need for a holistic analysis in future studies of both system design and use, within and beyond the intra-organisational boundaries for a truer understanding of sustainability 'management' control processes.

\section{Conclusion}

This study aimed to explore the broad characteristic type and use of control in SMEs through the implementation of an environmental management system (EMS). It found that the design of formalised controls tends to be characteristically formal and compliance-based to ensure environmental performance improvements are achieved at the operational level to meet ISO 14001 certification. Notwithstanding, these formal control instruments are complemented by extra-organisational factors (i.e. the individual sustainability values of SME owner-managers and employees) 
in the investigated SMEs. In this sense, local level operator knowledge is not only the product of formalised SCS design through EMS implementation, which appears to condition a primarily formal characteristic type of control in the studied SMEs, but is also built on the internal value systems of SME employees. Particularly, the findings reveal that daily tasks in situ are also achieved by engaging non-managerial employees through their intrinsic motivations and passionate interests, which may come from the extra-organisational context. This suggests, in extension to previous sustainability control research which places emphasise on organisational beliefs systems or values about sustainability, that individual values and/or intrinsic motivations to perform are also important for improving sustainability performance in situ and should not be downplayed in future sustainability control research (Johnstone, 2019).

\subsection{Theoretical implications}

Theoretically, this study offers various contributions.

First, this study is the first to use and support the key propositions presented in Johnstone's (2019) framework of sustainability control through an empirical research design. It contributes by emphasising the interplay between strategic and operational levels (i.e. system design and use) which should not and cannot be separated analytically in research practice for the SME context and beyond. It echoes Johnstone's assertion that using extant MCS frameworks for sustainability control research-from a strategic or managerial perspective (e.g. Arjaliès \& Mundy 2013; Rodrigue et al., 2013; Adib et al., 2020; Wijethilake \& Upadhaya, 2020)—are insufficient to fully explain how sustainability control is received, used and developed in situ (operationally) for sustainable performance improvements.

Notwithstanding, contrasting and building on Johnstone's work, the findings of this study highlight that for the case of SMEs, with shorter chains of command, the distinction between the analytical levels of control over and control in situ are increasingly blurred. This is because SME owner-managers often occupy the dual roles of leaders and team members which Johnstone's framework does not account for. Moreover, the findings of this study suggest that control in the studied SMEs is still primarily a top-down phenomenon given that the extent to which non-managerial operators contribute to system (re)design was minimal. In this sense, a formalised approach to control was stronger and primarily conditions action for the studied SMEs in system (re)development than any extra-organisational individual sustainability values of both managerial and non-managerial employees. This finding may come as a surprise given that extant SME literature attaches importance to personal motives guiding sustainable behaviour (see e.g. Spence, 2016; Stubblefield Loucks et al., 2010). However, it may be due to the adoption of ISO 14001 as a higher order 'compliance mechanism' conditioning the formal character of controls within the SMEs (see Ahrens \& Khalifa, 2015). This suggests that future research should use Johnstone's (2019) framework for SMEs not formally accredited to ISO 14001 to establish if and how the characteristic type and use of control differs. 
Second, the study further contributes to sustainability control research in SMEs as an emerging stream of interest given their widespread pollution effects as the biggest sector of society (e.g. Ghosh et al., 2019; Pelz, 2019; Gibassier \& Alcouffe, 2018; Johnstone, 2020a). It suggests that the characteristic type and use of control in SMEs through the implementation of an EMS is primarily formal and compliance driven. Nevertheless, this study does not detail the control typologies and their interaction effects for the SME context. Therefore, future studies could look further into the constellation of controls used in the construction of the SCS in SMEs. This is important given that SMEs arguably require unique solutions to environmental management based on their distinct features (Aragón-Correa et al., 2008).

Third, this study contributes to understanding accounting as a social practice, not only resigned to organisational designed controls and the outcomes thereof, but also reflective of individual values (managerial and non-managerial) about sustainability as a discourse. Relatedly, this can be seen as a step towards a better understanding of the relationship between corporate and individual accountability as an internal phenomenon, beyond externally orientated accountability in terms of reporting and disclosure (e.g. Shearer, 2002; Unerman \& Bennett, 2004) or internally orientated accountability in terms of corporate governance structures (e.g. Glass et al. 2016; Saliterer \& Korac, 2013). Particularly, the role of formalised control instruments in inciting individual responsibility and accountability for sustainability is rarely explicated in extant research. Thus, future research could further investigate the connection between internal management control tools and individual accountability for sustainability beyond calculative accounts in terms of a broader responsibility perspective. This also has the potential for bridging critical and managerial positions in future studies.

Fourth, this study presents individual engagement (particularly of non-managerial employees) as key for effective environmental performance outcomes. To this end, it offers empirical examples of the design and use of reward and compensation mechanisms for sustainability control in SMEs, which are generally lacking in extant sustainability control literature (see Crutzen et al., 2017; Ghosh et al., 2019). Not only is the interplay between extrinsic and intrinsic rewards emphasised, but the findings also highlight the role of non-managerial operators as important for sustainable performance. Consequently, future research could build upon the use of gamification as a management control tool or look more deeply into the role of passionate interests (see Baxter et al., 2019) as a conceptual tool for sustainability control not only in SMEs, but other organisational forms. This would contribute to a better understanding of the role of the individual employee in the sustainability control process (see also Ghosh et al., 2019). Moreover, drawing out employee engagement as a key control mechanism may also be a fruitful avenue for future research. For example, individual engagement could be extended as a specific type of socio-ideological or cultural control that integrates with the other control typologies to produce certain behavioural outcomes by facilitating action.

Finally, this study extends previous research on standards by suggesting the move towards the use of ISO 14001 as a framework, rather than a compliance mechanism per se (see Brunsson \& Jacobsson, 2002) that conditions the design of particular internal management controls (see Ahrens \& Khalifa, 2015). This study focuses on 
ISO 14001 certified SMEs. Therefore, the type and nature of sustainability control in SMEs that do not have a formal EMS in place remains unclear. To address concerns over the role of ISO 14001 for improved environmental management, future research could build on this study to address the role of EMS for sustainability control through standards such as ISO 14001 in SMEs.

\subsection{Managerial implications}

This study highlights that engaging individual, non-managerial employees is valuable for sustainable futures. This engagement can be extrinsic and/or intrinsic in nature. SME owner-managers should therefore proactively involve employees in the development process of internal EMS to not only meet ISO 14001 accreditation, but also to improve internal operating efficiencies and performance outcomes, and thus sustainable futures beyond the firm. SME owner-managers should ensure supportive structures where employees are given the autonomy to be creative and innovative, thus contributing to future EMS design. They should also build on the perceived intrinsic values of employees in the design of formalised control instruments to improve performance. This can be achieved by using reward and compensation mechanisms.

ISO 14001 auditors may also gain some insight from this research. Particularly, the findings offer some interpretations into how the standard is received and used by SMEs in practice. This, in turn, helps highlight any potential problems in the implementation process of EMS.

Acknowledgements Earlier versions of this paper were presented at the Nordic Academy of Management, Vaasa, Finland, 2019 and at the Centre for Empirical Research on Organisational Control, Örebro University, Sweden. The author is extremely grateful for the comments received, especially those of Magnus Frostenson, Sabina Du Rietz and Peter Beusch who helped substantially improve earlier versions of this paper. Moreover, the comments of two anonymous reviewers and the editor, Thomas Guenther were extremely helpful to help refine the scope of this paper. Finally, this research was partially funded by the JanWallander and Tom Hedelius Foundation (P2015-0031:1).

Authors' contributions One, sole author. Responsible for conceptualisation, data gathering, analysis and writing of paper.

Funding Open access funding provided by Örebro University. This research was partially funded by the JanWallander and Tom Hedelius Foundation (P2015-0031:1).

\section{Declarations}

Conflict of interest The author declares that there is no conflict of interest.

Open Access This article is licensed under a Creative Commons Attribution 4.0 International License, which permits use, sharing, adaptation, distribution and reproduction in any medium or format, as long as you give appropriate credit to the original author(s) and the source, provide a link to the Creative Commons licence, and indicate if changes were made. The images or other third party material in this article are included in the article's Creative Commons licence, unless indicated otherwise in a credit line to the material. If material is not included in the article's Creative Commons licence and your intended use is not permitted by statutory regulation or exceeds the permitted use, you will need to obtain permission 
directly from the copyright holder. To view a copy of this licence, visit http://creativecommons.org/licen ses/by/4.0/.

\section{References}

Adib, M., Zhang, X., Zaid, M. A., \& Sahyouni, A. (2020). Management control system for corporate social responsibility implementation-A stakeholder perspective. Corporate Governance: the International Journal of Business in Society. https://doi.org/10.1108/CG-06-2020-0247

Adler, P. S., \& Borys, B. (1996). Two types of bureaucracy: Enabling and coercive. Administrative Science Quarterly, 41(1), 61-89.

Ahrens, T., \& Chapman, C. S. (2007). Management accounting as practice. Accounting, Organizations and Society, 32(1-2), 1-27. https://doi.org/10.1016/j.aos.2006.09.013

Ahrens, T., \& Khalifa, R. (2015). The impact of regulation on management control. Qualitative Research in Accounting \& Management, 12(2), 106-126. https://doi.org/10.1108/QRAM-04-2015-0041

Albelda, E. (2011). The role of management accounting practices as facilitators of the environmental management: Evidence from EMAS organisations. Sustainability Accounting, Management and Policy Journal, 2(1), 76-100. https://doi.org/10.1108/20408021111162137

Albelda Pérez, E., Correa Ruiz, C., \& Carrasco Fenech, F. (2007). Environmental management systems as an embedding mechanism: A research note. Accounting, Auditing \& Accountability Journal, 20(3), 403-422. https://doi.org/10.1108/09513570710748562

Aragón-Correa, J. A., Hurtado-Torres, N., Sharma, S., \& García-Morales, V. J. (2008). Environmental strategy and performance in small firms: A resource-based perspective. Journal of Environmental Management, 86(1), 88-103. https://doi.org/10.1016/j.jenvman.2006.11.022

Arjaliès, D. L., \& Mundy, J. (2013). The use of management control systems to manage CSR strategy: A levers of control perspective. Management Accounting Research, 24(4), 284-300. https://doi.org/10. 1016/j.mar.2013.06.003

Baird, K., Su, S., \& Munir, R. (2017). The relationship between the enabling use of controls, employee empowerment and performance. Personnel Review, 47(1), 257-274. https://doi.org/10.1108/ PR-12-2016-0324

Baker, M. L., Brown, D. A., \& Malmi, T. (2012). An integrated package of environmental management control systems. In G. N. Gregoriou \& N. Finch (Eds.), Best practices in management accounting (pp. 115-129). Palgrave Macmillan.

Baker, C. R., Cohanier, B., \& Gibassier, D. (2018). Environmental management controls at MichelinHow do they link to sustainability? Social and Environmental Accountability Journal, 38(1), 75-96. https://doi.org/10.1080/0969160X.2018.1438300

Baxter, J., Carlsson-Wall, M., Chua, W. F., \& Kraus, K. (2019). Accounting and passionate interests: The case of a Swedish football club. Accounting, Organizations and Society, 74, 21-40. https://doi.org/ 10.1016/j.aos.2018.08.002

Bedford, D. S., \& Malmi, T. (2015). Configurations of control: An exploratory analysis. Management Accounting Research, 27, 2-26. https://doi.org/10.1016/j.mar.2015.04.002

Berry, M. A., \& Rondinelli, D. A. (1998). Proactive corporate environmental management: A new industrial revolution. Academy of Management Perspectives, 12(2), 38-50. https://doi.org/10.5465/ame. 1998.650515

Boiral, O. (2007). Corporate greening through ISO 14001: A rational myth?". Organization Science, 18(1), 127-146. https://doi.org/10.1287/orsc.1060.0224

Boiral, O., Guillaumie, L., Heras-Saizarbitoria, I., \& Tayo Tene, C. V. (2018). Adoption and outcomes of ISO 14001: A systematic review. International Journal of Management Reviews, 20(2), 411-432. https://doi.org/10.1111/ijmr.12139

Broadbent, J., \& Laughlin, R. (2009). Performance management systems: A conceptual model. Management Accounting Research, 20(4), 283-295. https://doi.org/10.1016/j.mar.2009.07.004

Brunsson, N., \& Jacobsson, B. (2002). A world of standards. Oxford University Press.

Burns, J., \& Scapens, R. W. (2000). Conceptualizing management accounting change: An institutional framework. Management Accounting Research, 11(1), 3-25. https://doi.org/10.1006/mare.1999. 0119 
Chapman, C. S., \& Kihn, L. A. (2009). Information system integration, enabling control and performance. Accounting, Organizations and Society, 34(2), 151-169. https://doi.org/10.1016/j.aos.2008. 07.003

Coyte, R. (2019). Enabling management control systems, situated learning and intellectual capital development. Accounting, Auditing \& Accountability Journal, 32(4), 1073-1097. https://doi.org/10.1108/ AAAJ-02-2013-1237

Crutzen, N., Zvezdov, D., \& Schaltegger, S. (2017). Sustainability and management control. Exploring and theorizing control patterns in large European firms. Journal of Cleaner Production, 143, 12911301. https://doi.org/10.1016/j.jclepro.2016.11.135

De Haan, G. (2006). The BLK '21'programme in Germany: A 'Gestaltungskompetenz'-based model for Education for Sustainable Development. Environmental Education Research, 12(1), 19-32.

Deegan, C. (2017). Twenty-five years of social and environmental accounting research within Critical Perspectives of Accounting: Hits, misses and ways forward. Critical Perspectives on Accounting, 43, 65-87. https://doi.org/10.1016/j.cpa.2016.06.005

Durden, C. (2007). Towards a socially responsible management control system. Accounting, Auditing \& Accountability Journal, 21(5), 671-694. https://doi.org/10.1108/09513570810872969

Duréndez, A., Ruíz-Palomo, D., García-Pérez-de-Lema, D., \& Diéguez-Soto, J. (2016). Management controlsystems and performance in small and medium family firms. European Journal of family business, 6(1), 10-20. https://doi.org/10.1016/j.ejfb.2016.05.001

Englund, H., \& Gerdin, J. (2015). Developing enabling performance measurement systems: On the interplay between numbers and operational knowledge. European Accounting Review, 24(2), 277-303. https://doi.org/10.1080/09638180.2014.918517

European Union Commission. (2003). Commission recommendation of 6 May 2003 concerning the definition ofmicro, small and medium-sized enterprises. Official Journal of the European union, 46(L124), 36-41.

Fassin, Y. (2008). SMEs and the fallacy of formalising CSR". Business Ethics: A European Review, 17(4), 364-378. https://doi.org/10.1111/j.1467-8608.2008.00540.x

Ghosh, B., Herzig, C., \& Mangena, M. (2019). Controlling for sustainability strategies: Findings from research and directions for the future. Journal of Management Control, 30(1), 5-24. https://doi.org/ 10.1007/s00187-019-00279-8

Gibassier, D., \& Alcouffe, S. (2018). Environmental management accounting: The missing link to sustainability? Social and Environmental Accountability Journal, 38(1), 1-18. https://doi.org/10.1080/ 0969160X.2018.1437057

Glass, C., Cook, A., \& Ingersoll, A. R. (2016). Do women leaders promote sustainability? Analyzing the effect of corporate governance composition on environmental performance. Business Strategy and the Environment, 25(7), 495-511. https://doi.org/10.1002/bse.1879

Gond, J. P., Grubnic, S., Herzig, C., \& Moon, J. (2012). Configuring management control systems: Theorizing the integration of strategy and sustainability. Management Accounting Research, 23(3), 205223. https://doi.org/10.1016/j.mar.2012.06.003

Goretzki, L., Strauss, E., \& Wiegmann, L. (2018). Exploring the roles of vernacular accounting systems in the development of "enabling" global accounting and control systems. Contemporary Accounting Research, 35(4), 1888-1916. https://doi.org/10.1111/1911-3846.12357

Graafland, J. J. (2018). Ecological impacts of the ISO14001 certification of small and medium sized enterprises in Europe and the mediating role of networks. Journal of Cleaner Production, 174, $273-$ 282. https://doi.org/10.1016/j.jclepro.2017.10.322

Graafland, J., \& Smid, H. (2016). Environmental impacts of SMEs and the effects of formal management tools: Evidence from EU's largest survey. Corporate Social Responsibility and Environmental Management, 23(5), 297-307. https://doi.org/10.1002/csr.1376

Granly, B. M., \& Welo, T. (2014). EMS and sustainability: Experiences with ISO 14001 and Eco-Lighthouse in Norwegian metal processing SMEs. Journal of Cleaner Production, 64, 194-204. https:// doi.org/10.1016/j.jclepro.2013.08.007

Gray, R. (2010). Is accounting for sustainability actually accounting for sustainability... and how would we know? An exploration of narratives of organisations and the planet. Accounting, Organizations and Society, 35(1), 47-62. https://doi.org/10.1016/j.aos.2009.04.006

Groen, B. A., van de Belt, M., \& Wilderom, C. P. (2012). Enabling performance measurement in a small professional service firm. International Journal of Productivity and Performance Management, 61(8), 839-862. https://doi.org/10.1108/17410401211277110 
Grubnic, S., Herzig, C., Gond, J. P., \& Moon, J. (2015). A new era-extending environmental impact to a broader sustainability agenda: The case of Commercial Group. Social and Environmental Accountability Journal, 35(3), 176-193. https://doi.org/10.1080/0969160X.2015.1096804

Guenther, E., Endrikat, J., \& Guenther, T. W. (2016). Environmental management control systems: aconceptualization and a review of the empirical evidence. Journal of Cleaner Production, 136, 147171. https://doi.org/10.1016/j.jclepro.2016.02.043

Halme, M., \& Korpela, M. (2014). Responsible innovation toward sustainable development in small and medium-sized enterprises: A resource perspective. Business Strategy and the Environment, 23(8), 547-566. https://doi.org/10.1002/bse.1801

Harris, E., Herzig, C., De Loo, I., \& Manochin, M. (2019). Management accounting and control for sustainability and strategic decision making. Journal of Management Control, 30(1), 1-4. https://doi. org/10.1007/s00187-019-00278-9

Heggen, C., Sridharan, V. G., \& Subramaniam, N. (2018). To the letter versus the spirit: A case analysis of contrasting environmental management responses. Accounting, Auditing and Accountability Journal, 31(2), 478-502. https://doi.org/10.1108/AAAJ-02-2016-2418

Henri, J. F., \& Journeault, M. (2010). Eco-control: The influence of management control systems on environmental and economic performance. Accounting, Organizations and Society, 35(1), 63-80. https://doi.org/10.1016/j.aos.2009.02.001

Heras-Saizarbitoria, I., \& Boiral, O. (2013). ISO 9001 and ISO 14001: Towards a research agenda on management system standards. International Journal of Management Reviews, 15(1), 47-65. https://doi.org/10.1111/j.1468-2370.2012.00334.x

Hillary, R. (2004). Environmental management systems and the smaller enterprise". Journal of Cleaner Production, 12(6), 561-569. https://doi.org/10.1016/j.jclepro.2003.08.006

ISO 14001: 2015 (2015) ISO 14001: Environmental management systems-Requirements with guidance for use. The International Standards Organisation.

Johnson, M. P. (2017). Knowledge acquisition and development in sustainability oriented small and medium-sized enterprises: Exploring the practices, capabilities and cooperation. Journal of Cleaner Production., 142, 3769-3781. https://doi.org/10.1016/j.jclepro.2016.10.087

Johnstone, L. (2019). Theorising and conceptualising the sustainability control system for effective sustainability management. Journal of Management Control, 30(1), 25-64. https://doi.org/10. 1007/s00187-019-00277-w

Johnstone, L. (2020a). A systematic analysis of environmental management systems in SMEs: Possible research directions from a management accounting and control stance. Journal of Cleaner Production. https://doi.org/10.1016/j.jclepro.2019.118802

Johnstone, L. (2020b). The construction of environmental performance in ISO 14001-certified SMEs. Journal of Cleaner Production. https://doi.org/10.1016/j.jclepro.2020.121559

Johnstone, L., \& Hallberg, P. (2020). ISO 14001 adoption and environmental performance in small to medium sized enterprises. Journal of Environmental Management. https://doi.org/10.1016/j. jenvman.2020.110592

Jordan, S., \& Messner, M. (2012). Enabling control and the problem of incomplete performance indicators. Accounting, Organizations and Society, 37(8), 544-564. https://doi.org/10.1016/j.aos. 2012.08.002

Journeault, M., De Rongé, Y., \& Henri, J. F. (2016). Levers of eco-control and competitive environmental strategy. The British Accounting Review, 48, 316-340. https://doi.org/10.1016/j.bar.2016. 06.001

Kearins, K., Collins, E., \& Tregidga, H. (2010). Beyond corporate environmental management to a consideration of nature in visionary small enterprise. Business \& Society, 49, 512-547. https:// doi.org/10.1177/0007650310368988

Kruis, A. M., Speklé, R. F., \& Widener, S. K. (2016). The levers of control framework: An exploratory analysis of balance. Management Accounting Research, 32, 27-44. https://doi.org/10.1016/j. mar.2015.12.002

Laguir, L., Laguir, I., \& Tchemeni, E. (2019). Implementing CSR activities through management control systems. Accounting, Auditing \& Accountability Journal, 32(2), 531-555. https://doi.org/10. 1108/AAAJ-05-2016-2566

Lavia López, O., \& Hiebl, M. R. (2014). Management accounting in small and medium-sized enterprises: Current knowledge and avenues for further research. Journal of Management Accounting Research, 27(1), 81-119. https://doi.org/10.2308/jmar-50915 
Lewis, K. V., Cassells, S., \& Roxas, H. (2015). SMEs and the potential for a collaborative path to environmental responsibility. Business Strategy and the Environment, 24(8), 750-764. https:// doi.org/10.1002/bse. 1843

Lisi, I. E. (2015). Translating environmental motivations into performance: The role of environmental performance measurement systems. Management Accounting Research, 29, 27-44. https://doi. org/10.1016/j.mar.2015.06.001

Lueg, R., \& Radlach, R. (2016). Managing sustainable development with management control systems: A literaturereview. European Management Journal, 34(2), 158-171. https://doi.org/10.1016/j.emj. 2015.11.005.

Mazzi, A., Toniolo, S., Mason, M., Aguiari, F., \& Scipioni, A. (2016). What are the benefits and difficulties in adopting an environmental management system? The opinion of Italian organizations. Journal of Cleaner Production, 139, 873-885. https://doi.org/10.1016/j.jclepro.2016.08.053

Messner, M. (2009). The limits of accountability. Accounting, Organizations and Society, 34(8), 918938. https://doi.org/10.1016/j.aos.2009.07.003

Moore, G., \& Spence, L. (2006). Responsibility and small business. Journal of Business Ethics, 67, 219226. https://doi.org/10.1007/s10551-006-9180-8

Nawrocka, D. (2008). Environmental supply chain management, ISO 14001 and RoHS. How are small companies in the electronics sector managing? Corporate Social Responsibility and Environmental Management, 15(6), 349-360. https://doi.org/10.1002/csr.176

Norris, G., \& O’Dwyer, B. (2004). Motivating socially responsive decision making: The operation of management controls in a socially responsive organisation. The British Accounting Review, 36(2), 173-196. https://doi.org/10.1016/j.bar.2003.11.004

Pelz, M. (2019). Can management accounting be helpful for young and small companies? Systematic review of a paradox. International Journal of Management Reviews, 21(2), 256-274. https://doi.org/ 10.1111/ijmr.12197

Perez-Sanchez, D., Barton, J. R., \& Bower, D. (2003). Implementing environmental management in SMEs. Corporate Social Responsibility and Environmental Management, 10(2), 67-77. https://doi. org/10.1002/csr.37

Pondeville, S., Swaen, V., \& De Rongé, Y. (2013). Environmental management control systems: The role of contextual and strategic factors. Management Accounting Research, 24(4), 317-332. https://doi. org/10.1016/j.mar.2013.06.007

Quinn, M., Hiebl, M. R., Moores, K., \& Craig, J. B. (2018). Future research on management accounting and controlin family firms: suggestions linked to architecture, governance, entrepreneurship and stewardship. Journal ofManagement Control, 28(4), 529-546. https://doi.org/10.1007/ s00187-018-0257-1.

Riccaboni, A., \& Leone, E. L. (2010). Implementing strategies through management control systems: The case of sustainability. International Journal of Productivity and Performance Management, 59(2), 130-144. https://doi.org/10.1108/17410401011014221

Rinaldi, L. (2019). Accounting for sustainability governance: The enabling role of social and environmental accountability research. Social \& Environmental Accountability Journal, 30(1), 1-22. https://doi.org/10.1080/0969160X.2019.1578675

Roberts, J., \& Scapens, R. (1985). Accounting systems and systems of accountability-Understanding accounting practices in their organisational contexts. Accounting, Organizations and Society, 10(4), 443-456. https://doi.org/10.1016/0361-3682(85)90005-4

Rodrigue, M., Magnan, M., \& Boulianne, E. (2013). Stakeholders' influence on environmental strategy and performance indicators: A managerial perspective. Management Accounting Research, 24(4), 301-316. https://doi.org/10.1016/j.mar.2013.06.004

Rosanas, J. M., \& Velilla, M. (2005). The ethics of management control systems: Developing technical and moral values. Journal of Business Ethics, 57(1), 83-96. https://doi.org/10.1007/ s10551-004-3826-1

Saliterer, I., \& Korac, S. (2013). Performance information use by politicians and public managers for internal control and external accountability purposes. Critical Perspectives on Accounting, 24(7-8), 502-517. https://doi.org/10.1016/j.cpa.2013.08.001

Santos, G., Mendes, F., \& Barbosa, J. (2011). Certification and integration of management systems: the experience of Portuguese small and medium enterprises. Journal of Cleaner Production, 19(17-18), 1965-1974. https://doi.org/10.1016/j.jclepro.2011.06.017

Scapens, R. W. (2006). Understanding management accounting practices: A personal journey. The British Accounting Review, 38(1), 1-30. https://doi.org/10.1016/j.bar.2005.10.002 
Schaltegger, S., \& Wagner, M. (2008). Types of sustainable entrepreneurship and conditions for sustainability innovation: From the administration of a technical challenge to the management of an entrepreneurial opportunity. In S. Sharma, M. Starik, R. Wüstenhagen, \& J. Hamschmidt (Eds.), Advances on research in corporate sustainability (pp. 27-48). Edward Elgar.

Shearer, T. (2002). Ethics and accountability: From the for-itself to the for-the-other. Accounting, Organizations and Society, 27(6), 541-573. https://doi.org/10.1016/S0361-3682(01)00036-8

Sinclair, A. (1995). The chameleon of accountability: Forms and discourses. Accounting, Organizations and Society, 20(2-3), 219-237. https://doi.org/10.1016/0361-3682(93)E0003-Y

Soderstrom, K. M., Soderstrom, N. S., \& Stewart, C. R. (2017). Sustainability/CSR research in management accounting: A review of the literature. Advances in Management Accounting, 28, 59-85. https://doi.org/10.1108/S1474-787120170000028003

Spence, L. J. (2016). Small business social responsibility: Expanding core CSR theory. Business and Society, 55(1), 23-55. https://doi.org/10.1177/0007650314523256

Stubblefield Loucks, E., Martens, M. L., \& Cho, C. H. (2010). Engaging small-and medium-sized businesses in sustainability. Sustainability Accounting, Management and Policy Journal, 1(2), 178-200. https://doi.org/10.1108/20408021011089239

Sundin, H., \& Brown, D. A. (2017). Greening the black box: Integrating the environment and management control systems. Accounting, Auditing \& Accountability Journal, 30(3), 620-642. https://doi. org/10.1108/AAAJ-03-2014-1649

Tessier, S., \& Otley, D. (2012). A conceptual development of Simons' Levers of control framework. Management Accounting Research, 23(3), 171-185. https://doi.org/10.1016/j.mar.2012.04.003

Tung, A., Baird, K., \& Schoch, H. (2018). The effectiveness of using environmental performance measures. Australasian Journal of Environmental Management, 25(4), 459-474. https://doi.org/10.1080/ 14486563.2018 .1506366

Unerman, J., \& Bennett, M. (2004). Increased stakeholder dialogue and the internet: Towards greater corporate accountability or reinforcing capitalist hegemony? Accounting, Organizations and Society, 29(7), 685-707.

Wagner, M., \& Schaltegger, S. (2010). Classifying entrepreneurship for the public good: Empirical analysis of a conceptual framework. Journal of Small Business \& Entrepreneurship, 23(3), 431-443. https://doi.org/10.1080/08276331.2010.10593494

Wals, A. E. (2010). Mirroring, Gestaltswitching and transformative social learning: Stepping stones for developing sustainability competence. International Journal of Sustainability in Higher Education, 11(4), 380-390.

Wang, S., Wang, H., \& Wang, J. (2019). Exploring the effects of institutional pressures on the implementation of environmental management accounting: Do top management support and perceived benefit work? Business Strategy and the Environment, 28(1), 233-243. https://doi.org/10.1002/bse.2252

Wijethilake, C., Munir, R., \& Appuhami, R. (2018). Strategic responses to institutional pressures for sustainability: The role of management control systems. Accounting, Auditing and Accountability Journal, 30(8), 1677-1710. https://doi.org/10.1108/AAAJ-07-2015-2144

Wijethilake, C., \& Upadhaya, B. (2020). Market drivers of sustainability and sustainability learning capabilities: The moderating role of sustainability control systems. Business Strategy and the Environment. https://doi.org/10.1016/j.jenvman.2017.03.057

Witjes, S., Vermeulen, W. J., \& Cramer, J. M. (2017). Exploring corporate sustainability activities. Experiences from 18 small and medium sized enterprises in The Netherlands. Journal of Cleaner Production., 153, 528-538. https://doi.org/10.1016/j.jclepro.2016.02.027

Won Kim, N. K., \& Matsumura, E. M. (2017). Managerial accounting research in Corporate Social Responsibility: A framework and opportunities for research. Advances in Management Accounting, 28, 31-58.

Wouters, M., \& Wilderom, C. (2008). Developing performance-measurement systems as enabling formalization: A longitudinal field study of a logistics department. Accounting, Organizations and Society, 33(4), 488-516. https://doi.org/10.1016/j.aos.2007.05.002

Wu, G. C. (2017). Effects of socially responsible supplier development and sustainability-oriented innovation onsustainable development: Empirical evidence from SMEs. Corporate Social Responsibility and EnvironmentalManagement, 24(6), 661-675. https://doi.org/10.1002/csr.1435.

Publisher's Note Springer Nature remains neutral with regard to jurisdictional claims in published maps and institutional affiliations. 